\title{
Inventário e distribuição geográfica de Leguminosae no arquipélago de Marajó, PA, Brasil
}

\author{
Wanderson Luis da Silva e Silva ${ }^{1,3}$, Ely Simone Cajueiro Gurgel ${ }^{1}$, João Ubiratan Moreira dos Santos ${ }^{2}$ \\ e Mônica Falcão da Silva ${ }^{1}$
}

Recebido: 18.02.2013; aceito: 2.07.2013

\begin{abstract}
Inventory and geographical distribution of Leguminosae in the Marajó archipelago, Pará State, Brazil). Leguminosae is dominant in vegetation formations of Amazon and, in this context the Marajó Archipelago stands out for including several of these formations. This paper aimed to update and analyze the patterns of geographic distribution of Leguminosae from the Marajó archipelago. Data obtained from herbaria, literature and botanical expeditions thus the patterns of distribution were determined. We registered 241 species in 80 genera of which six are new records for the flora of Pará State. The most representative genera were Inga, Mimosa, Aeschynomene and Machaerium. Subfamily Papilionoideae had the greatest number of genera and species. Jacqueshuberia quinquangulata is endemic to Marajó Island. The phytogeographical analysis showed predominance of species widely distributed South America. The archipelago, because of its physiognomic heterogeneity, represents a diverse site of Leguminosae in Amazon, with about $31 \%$ of species diversity mentioned for the family in Pará.
\end{abstract}

Key words: Amazon, Fabaceae, floristic survey, phytogeography

RESUMO - (Inventário e distribuição geográfica de Leguminosae no arquipélago de Marajó, PA, Brasil). Leguminosae é dominante nas formações vegetacionais amazônicas; e, nesse contexto, o arquipélago de Marajó possui destaque, pois inclui várias dessas formações. Este trabalho objetiva fornecer uma listagem das espécies de Leguminosae registradas no arquipélago de Marajó e analisar a sua distribuição geográfica. Analisaram-se dados de herbários, literatura e coletas, e a partir de então foram definidos os padrões de distribuição. Foram registradas 241 espécies em 80 gêneros as quais seis são novos registros para o Estado do Pará. Os gêneros mais representativos foram Inga, Mimosa, Aeschynomene e Machaerium. A subfamília Papilionoideae apresentou maior número de gêneros e espécies. Jacqueshuberia quinquangulata é endêmica da região estudada. A análise da distribuição mostrou o predomínio de espécies amplamente distribuídas pela América do Sul. O arquipélago, por sua heterogeneidade fisionômica, é um sítio diverso de Leguminosae na Amazônia, com cerca de $30 \%$ da flora específica da família no Estado do Pará.

Palavras-chave: Amazônia, Fabaceae, fitogeografia, levantamento florístico

\section{Introdução}

A família Leguminosae é constituída por cerca de 727 gêneros e 19.325 espécies, tradicionalmente distribuídas em três subfamílias: Caesalpinioideae, Mimosoideae e Papilionoideae (Lewis et al. 2005); ocupa distintos ambientes das regiões tropicais, subtropicais e temperadas, aparecendo como uma das famílias de maior riqueza em florestas neotropicais (Gentry 1988).

Nas diferentes regiões fitogeográficas da Amazônia e da Guiana, as espécies de Leguminosae constam como elemento florístico dominante, desempenhando papéis ecológicos diversos e contribuindo significativamente com a diversidade regional, tanto em habitats florestais quanto não florestais (Salomão et al. 1988, Almeida et al. 1993, Boggan et al. 1997, Ferreira \& Prance 1998, Miranda \& Absy 2000, Oliveira 2000, Hopkins 2005, Funk et al. 2007). Ducke (1922, 1925, 1939, 1944, 1946, 1949) realizou estudos pioneiros sobre as Leguminosae ocorrentes na Amazônia, sendo esses os mais completos já elaborados sobre a família no âmbito regional.

1. Museu Paraense Emílio Goeldi, Coordenação de Botânica, Avenida Perimetral, 1901, Terra Firme, 66077-530 Belém, PA, Brasil

2. Universidade Federal Rural da Amazônia, Instituto de Ciências Agrárias, Av. Presidente Tancredo Neves 2501, Terra Firme, 66077-901 Belém, PA, Brasil

3. Autor para correspondência: wl.silvasilva@gmail.com 
O arquipélago de Marajó apresenta um complexo fisionômico único no contexto amazônico, com predomínio de campos naturais e florestas inundáveis e de terra firme, influenciadas principalmente pela variação sazonal da precipitação pluviométrica, rede de drenagem fluvial e topografia (Amaral et al. 2007). Por apresentar singular heterogeneidade ambiental, essa região foi citada com destaque nos diversos estudos fitogeográficos amazônicos (Ducke \& Black 1954, Pires 1973, Pires \& Prance 1985).

De acordo com Rossetti et al. (2010), a heterogeneidade local é resultado dos processos geológicos de formação da ilha de Marajó. Para esses autores, as diversas mudanças no ambiente físico alteraram a dinâmica de paleocanais, que controlavam parâmetros como tipo de solo, topografia e hidrologia. A porção leste, por exemplo, é formada basicamente por formações não florestais sobre solos rasos desenvolvidos sobre canais mais recentes, inundáveis ou não inundáveis, enquanto que os canais mais antigos sustentam formações florestais.

A ilha de Marajó, apesar de inserida em Unidade de Conservação (Área de Proteção Ambiental do arquipélago de Marajó), vem sofrendo constante pressão antrópica, por meio de atividades agropastoris e extrativismo madeireiro, fazendo com que parte do seu território, representado por diferentes zonas ecotonais, viesse a ser classificado como prioritário para a conservação da biodiversidade (Capobianco et al. 2001, MMA 2007).

Na região foram realizados diversos estudos com o intuito de classificar e descrever as fitofisionomias e ampliar o conhecimento sobre a composição florística (Huber 1898, 1902, 1943, Miranda 1909, Ducke \& Black 1954, Dias 1973, RADAMBRASIL 1974, Bastos 1984, Pires \& Prance 1985, Amaral et al. 2007), citando, em alguns casos, Leguminosae como elemento florístico de destaque. Entretanto, a região ainda carece de estudos com enfoque biogeográfico para a família, estudos esses que permitiriam compreender o dimensionamento espacial das espécies, servindo como ferramenta na definição dos graus de endemismo, estados de conservação, estudos evolutivos e classificação de áreas prioritárias para a conservação (Kerr 1997, Sylvestre 2002, Morrone 2004).

Apesar da dominância das Leguminosae no bioma amazônico, principalmente no arquipélago de Marajó, a família permanece pouco investigada, sendo citada apenas em levantamentos florísticos generalistas.
Portanto, este trabalho teve como objetivo atualizar o conhecimento sobre as espécies de Leguminosae do arquipélago de Marajó, analisando os padrões de distribuição geográfica, bem como identificando sua distribuição nos diferentes tipos de vegetação e domínios fitogeográficos do Brasil.

\section{Material e métodos}

O estudo foi realizado no arquipélago de Marajó, localizado no nordeste do Estado do Pará, com área de aproximadamente $59.000 \mathrm{~km}^{2}\left(0^{\circ} 46^{\prime} \mathrm{N}\right.$ a $1^{\circ} 48^{\prime} \mathrm{S}$ e $48^{\circ} 34^{\prime} \mathrm{W}$ a $\left.52^{\circ} 16^{\prime} \mathrm{W}\right)$. Caviana, Mexiana e Marajó são as ilhas mais importantes da região. Com área aproximada de $48.000 \mathrm{~km}^{2}$, a ilha de Marajó é considerada a maior ilha fluvial-marítima do mundo (Sioli 1964) (figura 1).

O clima da região, de acordo com a classificação de Köeppen, varia entre os tipos Afi e Aw (RADAMBRASIL 1974). A precipitação média anual oscila entre 2.750 e $3.000 \mathrm{~mm}$, sendo maior entre março e junho e menor entre setembro e novembro; a temperatura anual média é de $26^{\circ} \mathrm{C}$ e a umidade relativa é em torno de $86 \%$ (INMET 2012). A topografia é plana a suavemente ondulada, com solos predominantemente aluviais e hidromórficos de origem quaternária (RADAMBRASIL 1974, Amaral et al. 2007).

A ilha de Marajó possui duas regiões vegetacionais marcantes no sentido leste e oeste. Ao leste, constituída pelos municípios de Cachoeira do Ararí, Chaves, Muaná, Ponta de Pedras, Salvaterra, Santa Cruz do Ararí e Soure, estão situados os campos de terra firme sazonalmente inundados e vegetação com influência marinha (mangues e restingas). A porção oeste possui relevo mais elevado, acima de $20 \mathrm{~m}$ em alguns pontos, apresentando diversos canais, rios e pequenas ilhas, sendo denominada de região dos "furos de Breves". Nessa região, que incluí os municípios de Afuá, Anajás, Breves, Curralinho, Gurupá, Portel e São Sebastião da Boa Vista, predominam as florestas de terra firme, florestas inundáveis (várzea e igapós) e florestas secundárias (Pires 1973, RADAMBRASIL 1974, Amaral et al. 2007) (figura 2).

A listagem de Leguminosae foi realizada a partir da compilação das informações de: 1) coletas, utilizando o método de caminhamento aleatório (Filgueiras et al. 1994), entre maio e junho/2010 e junho e julho/2011, cobrindo a maior extensão possível das fitofisionomias; 2) análise das coleções de Leguminosae dos herbários que concentram os 
registros para o arquipélago de Marajó, MG, IAN, INPA e RB (acrônimos conforme Thiers 2012); 3 ) dados de literatura, com base na citação dos materiais examinados de revisões taxonômicas de grupos de Leguminosae com ocorrência no arquipélago de Marajó.

Os exemplares coletados foram incorporados ao Herbário João Murça Pires (MG), do Museu Paraense Emílio Goeldi. Materiais coletados e coleções consultadas nos herbários foram identificados com base em revisões taxonômicas, comparações com coleções certificadas por especialistas, tipos ou fotografias de tipos e obras originais, exceto aqueles já confirmados por especialistas.

As informações sobre a distribuição das espécies foram extraídas de revisões taxonômicas, checklists e floras regionais (Ducke 1925, Boggan et al. 1997, Barneby et al. 1998, Aymard et al. 1999, Barneby et al. 2001, Funk et al. 2007), sendo os padrões de distribuição geográfica definidos de acordo com seus limites de distribuição (Queiroz 2006), sejam esses contínuos ou descontínuos. Feito isso, os padrões de distribuição geográfica foram estabelecidos em macrorregiões, adaptadas de Kelloff \& Funk (2004). Para espécies com distribuição restrita à América do Sul ou ao Brasil, os padrões foram mais detalhados, sendo adaptados de Kelloff \& Funk (2004), Morim (2006) e Flores \& Rodrigues (2010). Os registros por domínio fitogeográfico foram obtidos na literatura e na Lista de Espécies da Flora do Brasil - Fabaceae (Lima et al. 2012).
Os dados referentes aos hábitos e fitofisionomias (habitats) foram obtidos de observações no campo, de exsicatas e de literatura. A classificação dos habitats foi adaptada de Pires (1973) e RADAMBRASIL (1974), separando-se a vegetação em dois grupos: 1) florestas de terra firme (FTF) ou inundável (FI), como várzeas, igapós e mangues; e 2) vegetação aberta bem drenada (VABD), como campos de terra firme, restingas e áreas antropizadas, e mal drenada (VAMD), como campos sazonalmente inundáveis. A classificação dos tipos de hábito foi adaptada das propostas de Ferri et al. (1981) e IBGE (2012), exceto espécies trepadeiras, baseadas em Queiroz (2009).

Para a disposição em subfamílias foram adotadas as propostas de Lewis et al. (2005). Categorias infraespecíficas não foram consideradas e ajustes de sinonímia, quando necessário, foram realizados com base nas circunscrições mais recentes. É citado apenas um material testemunho (voucher) por espécie ocorrente no arquipélago de Marajó (tabela 1).

\section{Resultados e discussão}

Por meio da compilação das informações, foram registradas 241 espécies de Leguminosae na área de estudo, pertencentes a 80 gêneros (tabela 1), valores expressivos em relação à flora do Estado do Pará, que representa aproximadamente $31 \%$ da flora específica da família citada para esse Estado (Lima et al. 2012). Entre as subfamílias, destaca-se Papilionoideae, com maior riqueza, tanto em de gêneros (43) como número de espécies (109). A subfamília Caesalpinioideae

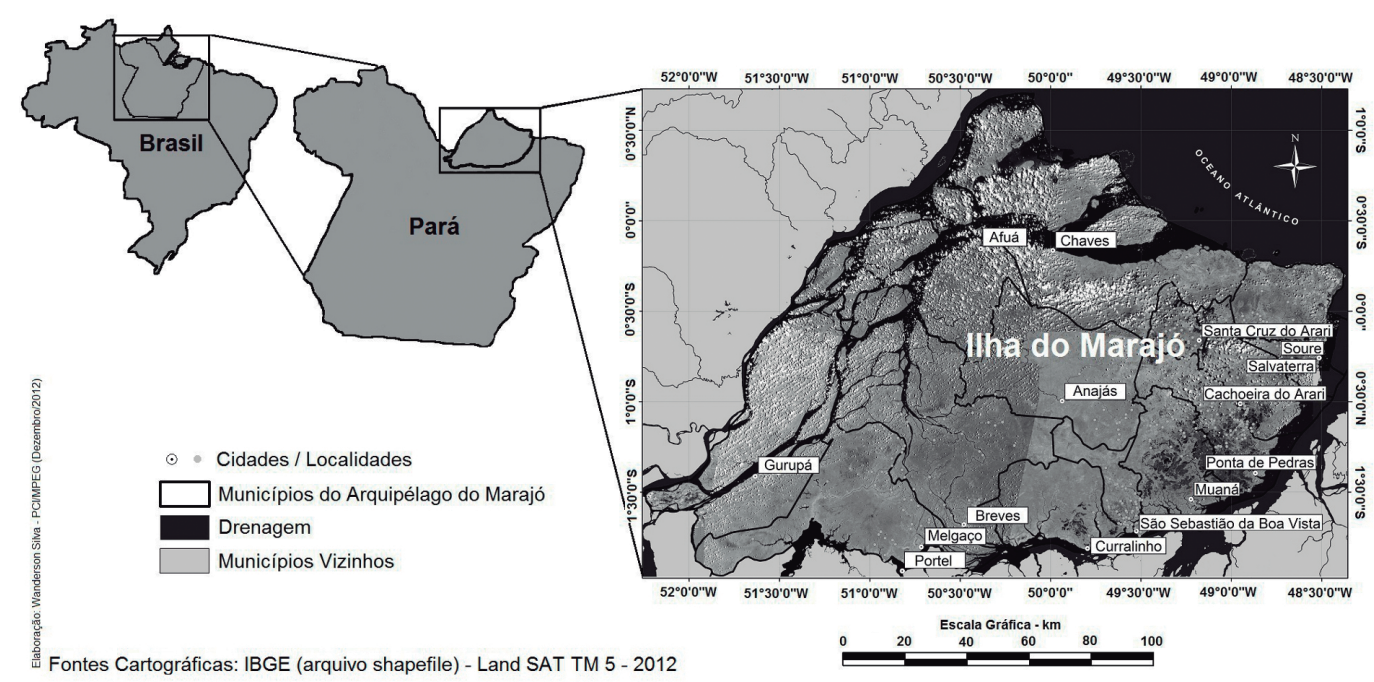

Figura 1 - Localização da área de estudo no Estado do Pará, Brasil.

Figure 1 - Location of the study area in the Pará State, Brazil. 


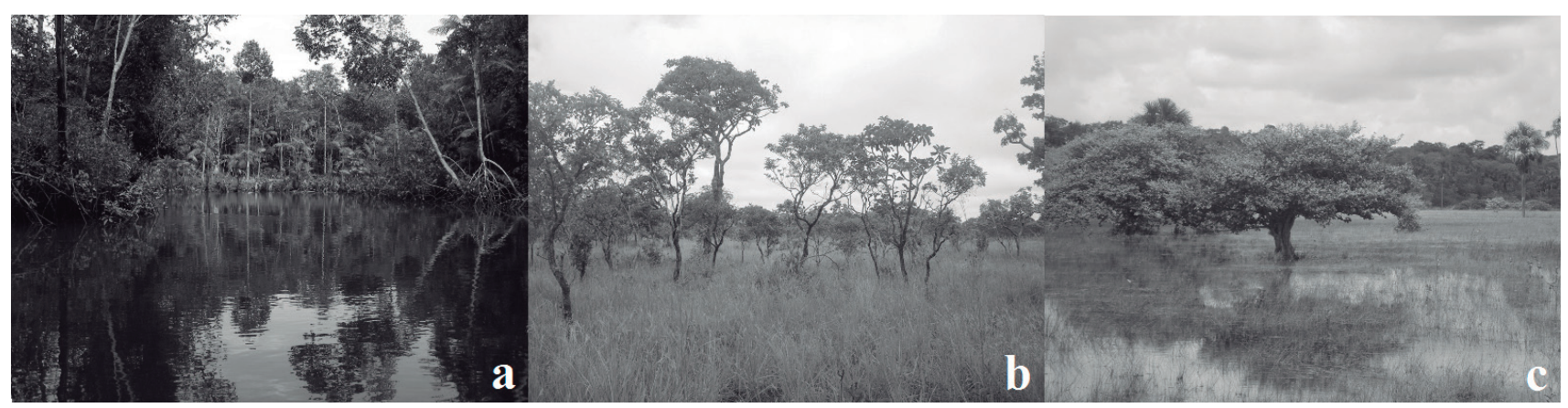

Figura 2 - Exemplos de algumas fitofisionomias encontradas no Arquipélago de Marajó, PA, Brasil. a. Floresta de várzea, município de Muaná. b. Campo de terra firme, município de Salvaterra. c. Campo inundável, município de Salvaterra. Imagens: André Olmos Simões, 2011 (c); Wanderson Luis da Silva, 2010 (a, b).

Figure 2 - Some types of vegetation found in the Marajó archipelago, Pará State, Brazil. a. Floodplain forest, municipality of Muaná b. Grasslands, municipality of Salvaterra. c. Floodable grasslands, municipality of Salvaterra. Images: André Olmos Simões, 2011 (c); Wanderson Luis da Silva, 2010 (a, b).

foi representada por 19 gêneros e 56 espécies e Mimosoideae por 18 gêneros e 76 espécies. O número de espécies obtido para o arquipélago de Marajó é superior aos 121 táxons específicos registrados para a família em fisionomias florestais e não florestais da ilha de Maracá, Roraima (Lewis \& Owen 1989), apresentando 47 espécies em comum com o presente estudo, principalmente entre as de ampla distribuição nas Américas.

Distribuídas entre as distintas fitofisionomias do arquipélago de Marajó, as espécies de Leguminosae ocorrem como árvores (121 espécies - 50,2\%), subarbustos (20 espécies - 8,3\%), lianas (19 espécies $7,9 \%)$, ervas (16 espécies - 6,6\%), arbustos (13 espécies - 5,4\%), trepadeiras herbáceas (12 espécies $-5,0 \%$ ) e arbustos escandentes (cinco espécies - 2,1\%). A combinação de hábitos ocorreu em 35 espécies (14,5\% do total), como arbustos ou árvores (doze espécies - 5,0\%), arbustos escandentes ou árvores (nove espécies - 3,7\%), subarbustos ou arbustos (sete espécies - 2,9\%), ervas ou subarbustos (seis espécies $2,5 \%$ ) e arbustos escandentes ou lianas (uma espécie - 0,4\%). Essa combinação ocorreu principalmente em representantes de Dalbergia, Machaerium e Senna, gêneros que possuem grande plasticidade quanto ao hábito, influenciados principalmente pelos estágios de desenvolvimento.

Os gêneros Inga (32 espécies), Mimosa (11), Aeschynomene (10) e Machaerium (10) apresentaram maior riqueza em relação ao número de espécies (26,1\% do total). Os representantes de Inga e Machaerium predominaram em formações florestais com habitat preferencialmente sujeito à inundação, como registrado por Bastos (1987), Almeida et al. (2004), Amaral et al. (2007) e Carim et al. (2008) para esse tipo de ambiente. Mimosa e Aeschynomene predominaram, respectivamente, em formações abertas mal drenadas e bem drenadas, como também registrado por Miranda \& Absy (2000), Bove et al. (2003), Flores \& Rodrigues (2010) e Moreira et al. (2011). Em pouco mais de $46 \%$ dos gêneros registrados ocorreram apenas uma espécie, com hábito predominantemente arbóreo.

Das espécies registradas no presente estudo, seis (indicadas na tabela 1 por asteriscos) não haviam sido citadas para o Estado do Pará na Lista das espécies de Leguminosae da Flora do Brasil (Lima et al. 2012): Eperua duckeana Cowan, Inga brachyrhachis Harms, Mimosa pigra L., Arachis dardanii Krapov. \& W.C. Gregory, Derris floribunda (Benth.) Ducke e Sesbania herbacea (Mill.) McVaugh. Apesar de também não citadas nessa lista, Cynometra marginata Benth., Tachigali paniculata Aubl., Hydrochorea corymbosa (Rich.) Barneby \& J.W.Grimes, Inga ingoides (Rich.) Willd., Inga micradenia Spruce ex Benth., Inga nobilis Willd., Macrosamanea spruceana (Benth.) Killip in Record e Dalbergia ovalis (L.) P.L.R. Moraes \& L.P. Queiroz, foram mencionadas para o Estado do Pará por Ducke (1925). Dalbergia ovalis é citada por sua sinonímia na Lista da Flora do Brasil, Dalbergia monetaria L.f., sendo este nome tratado atualmente como ilegítimo (Moraes 2012).

Sesbania herbacea, nativa da América do Norte, possui distribuição neotropical e não foi citada para o Brasil por Lima et al. (2012), contudo o foi por Farruggia (2009), que registrou sua ocorrência ao 


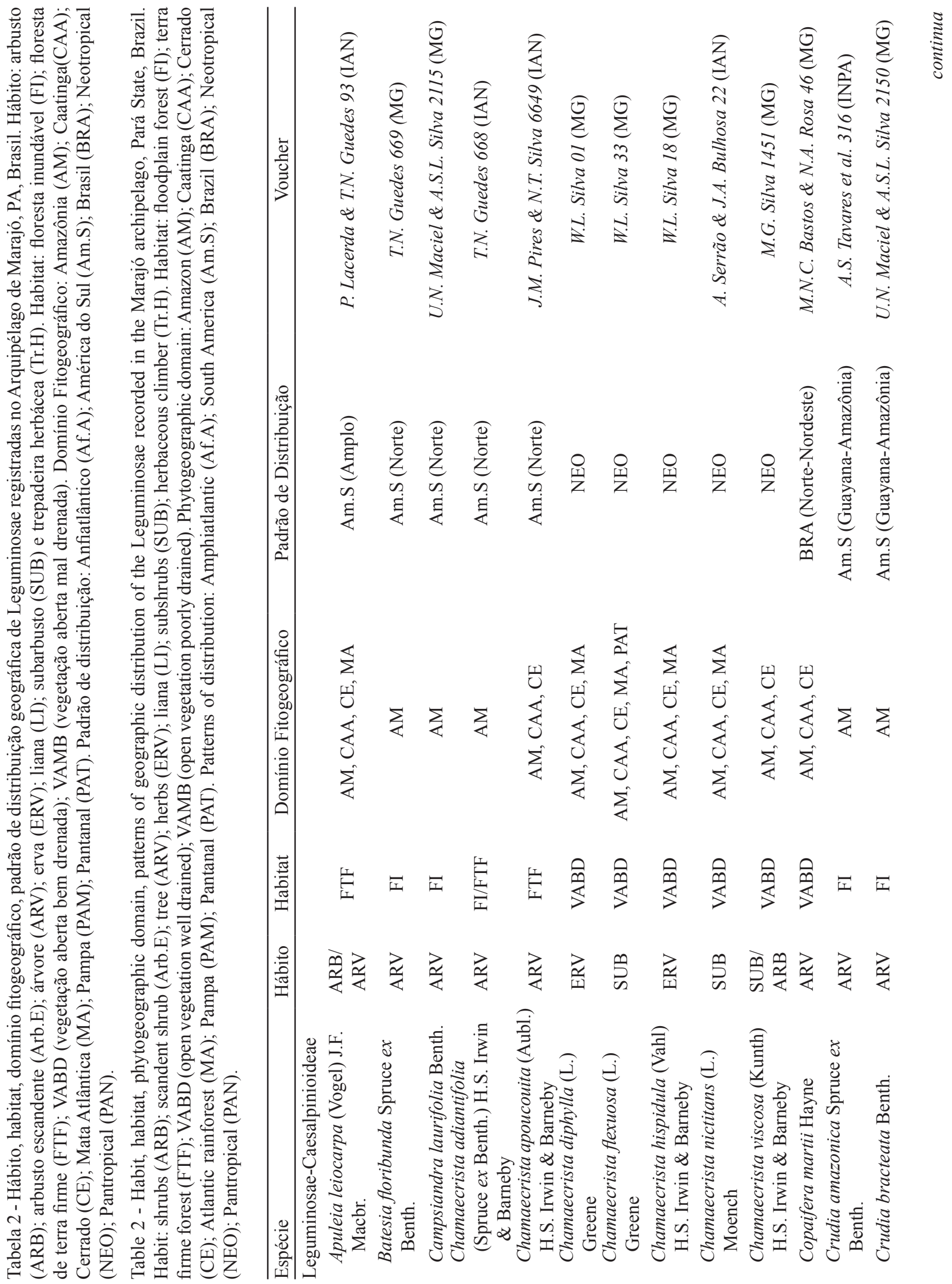




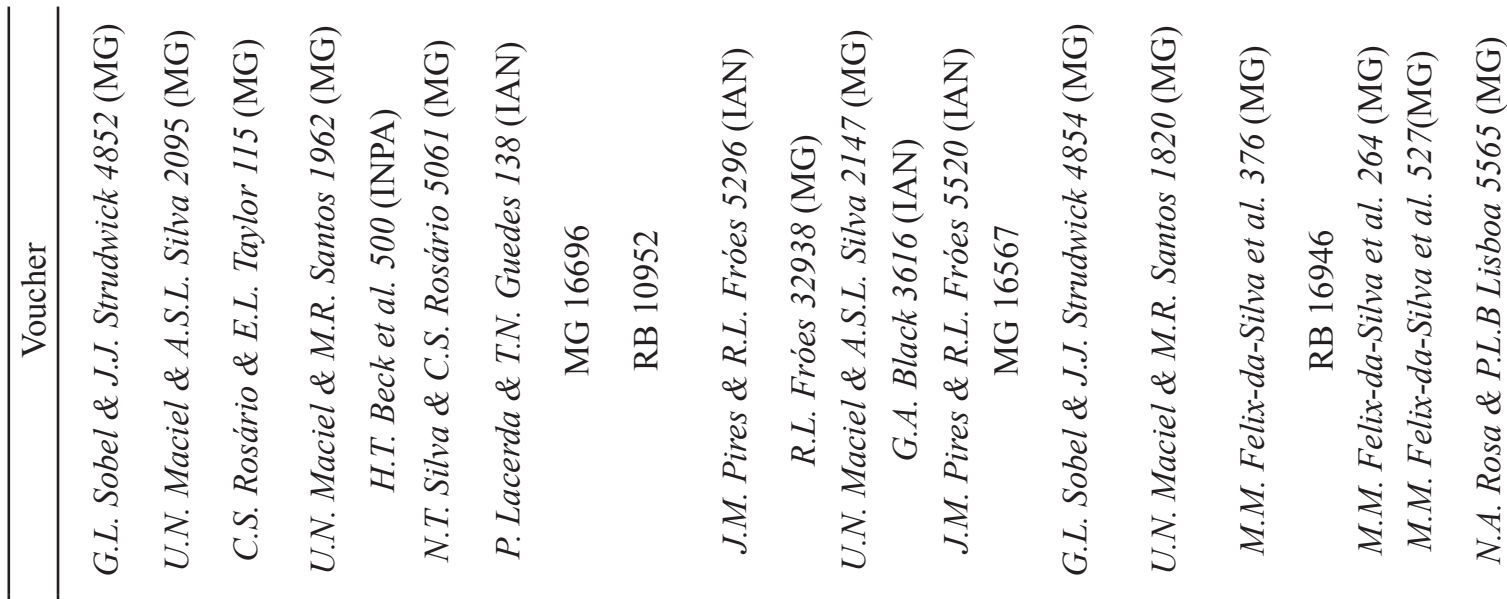

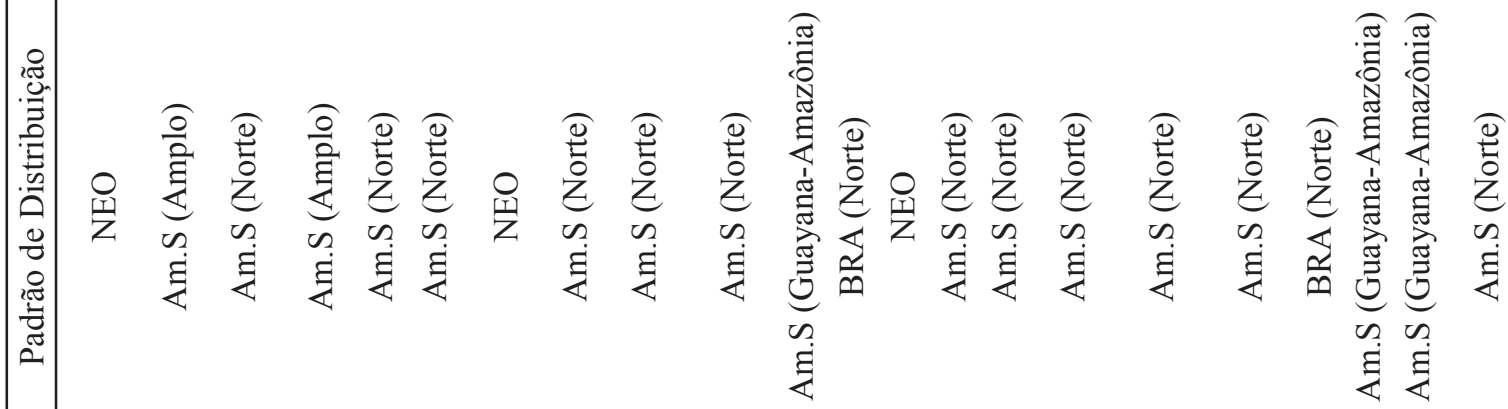

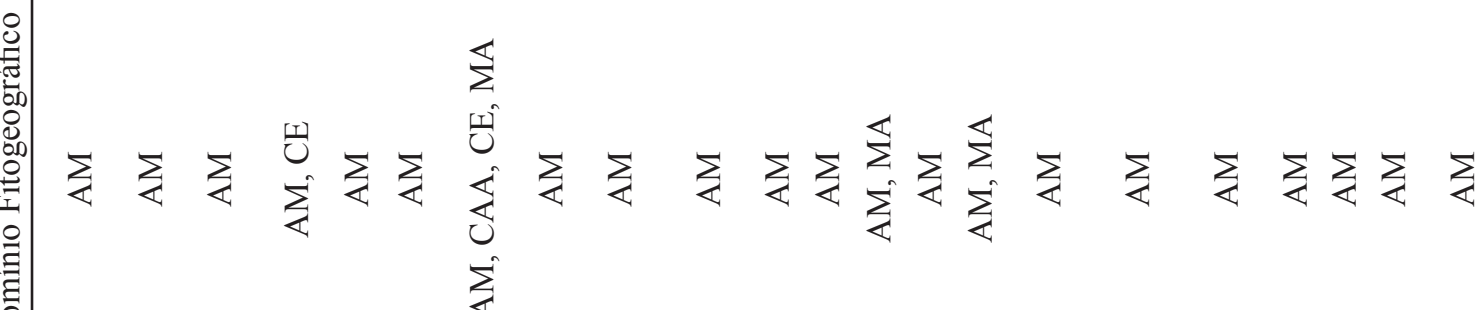

○े

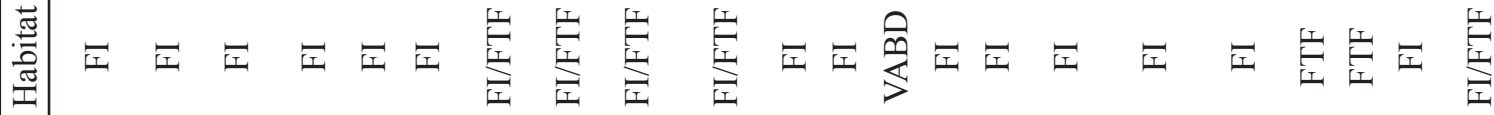

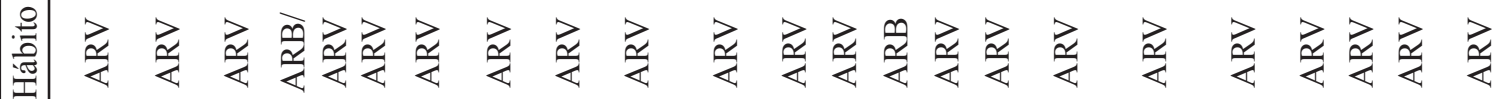

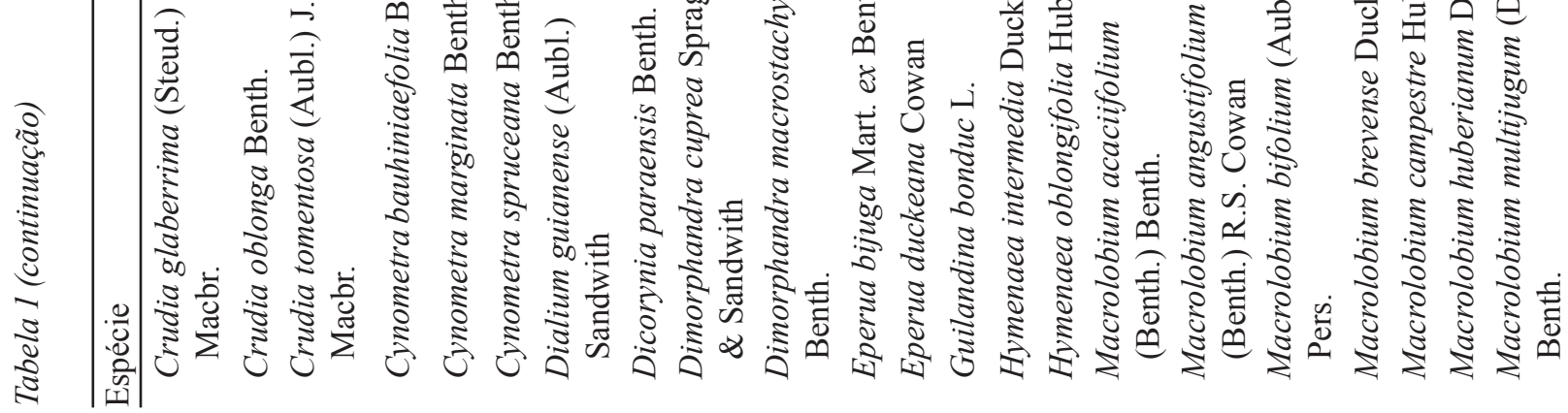




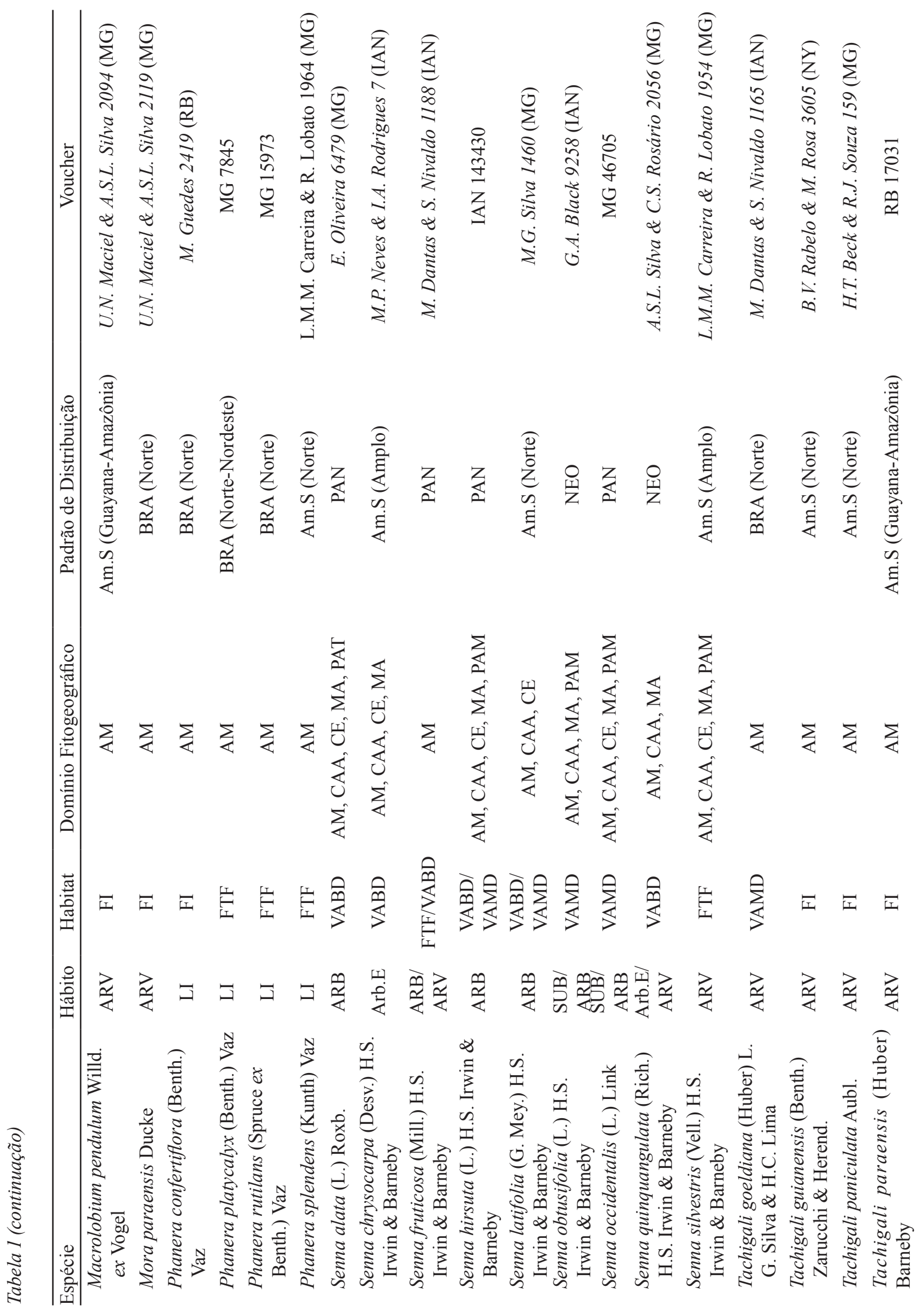




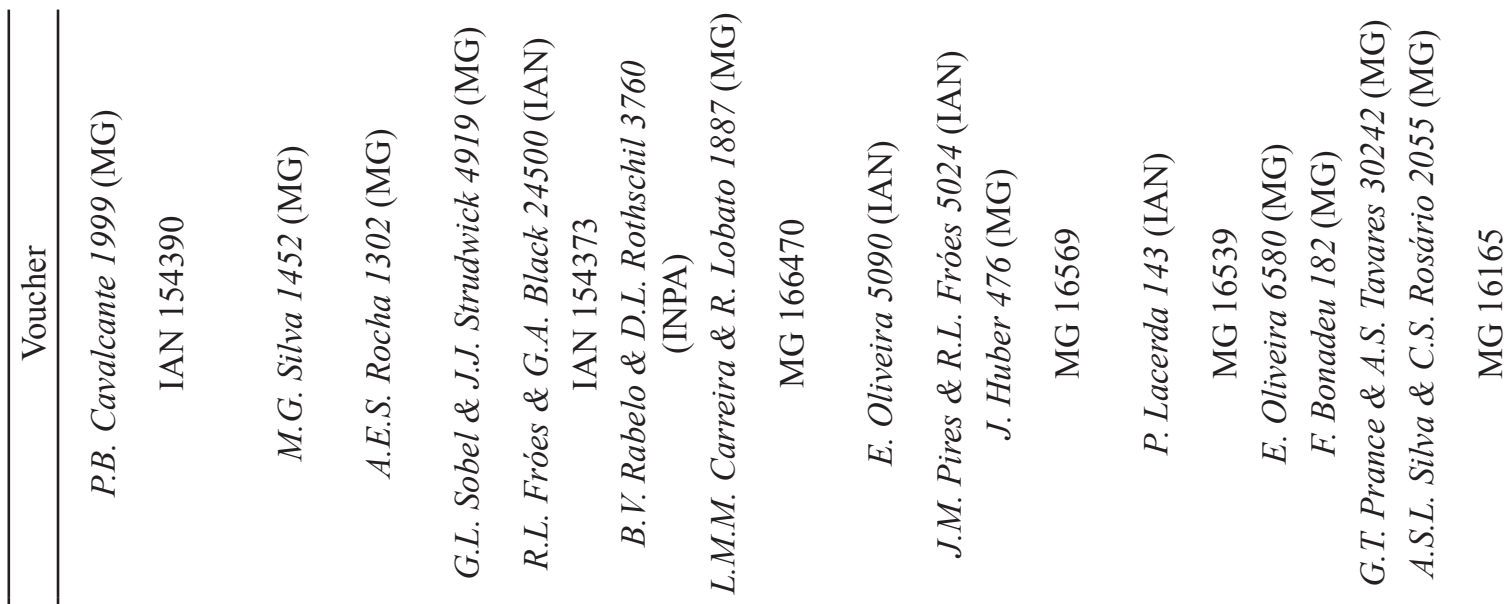

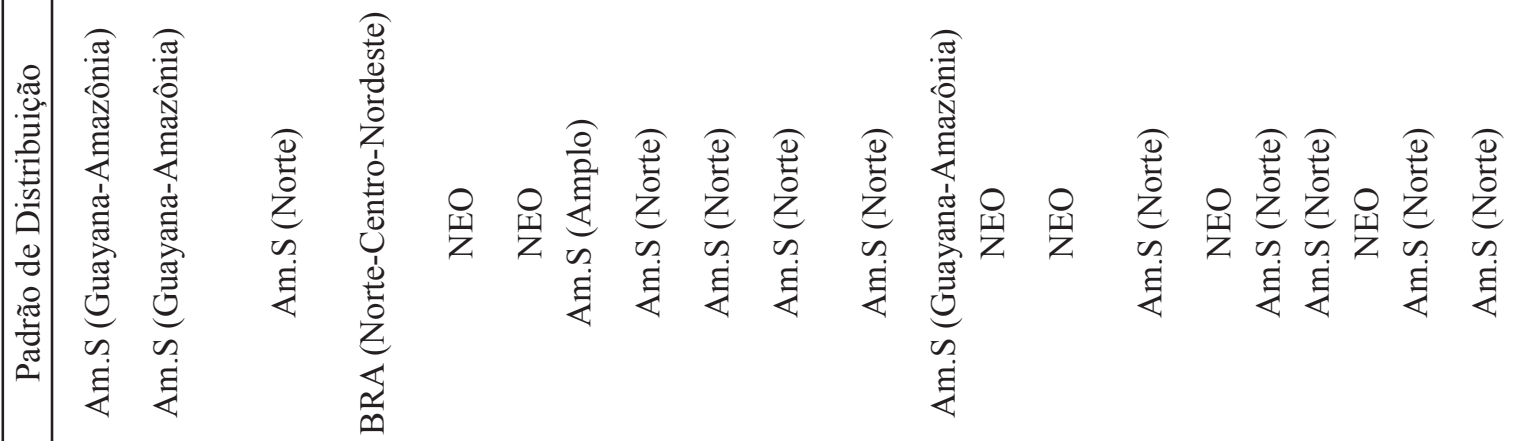

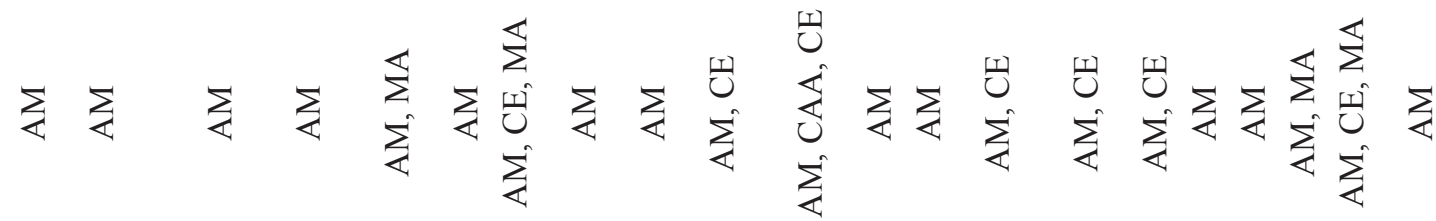

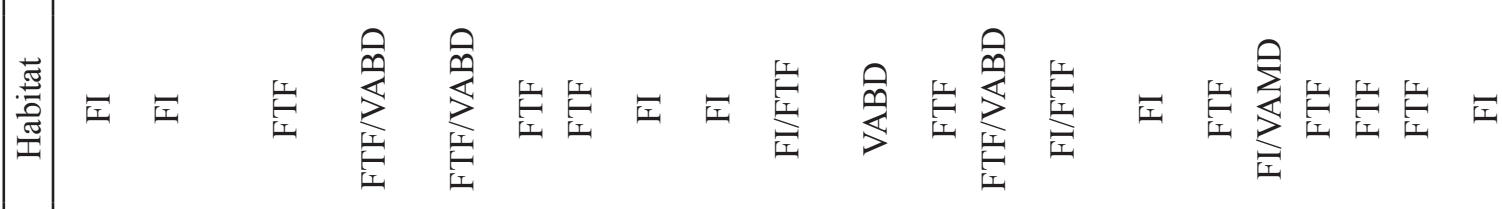

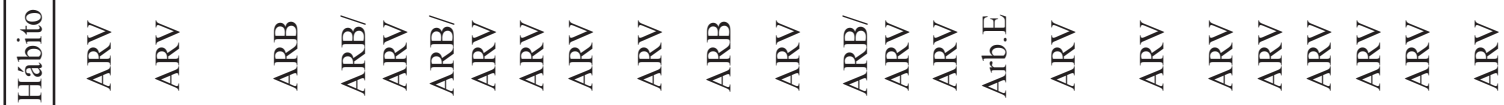

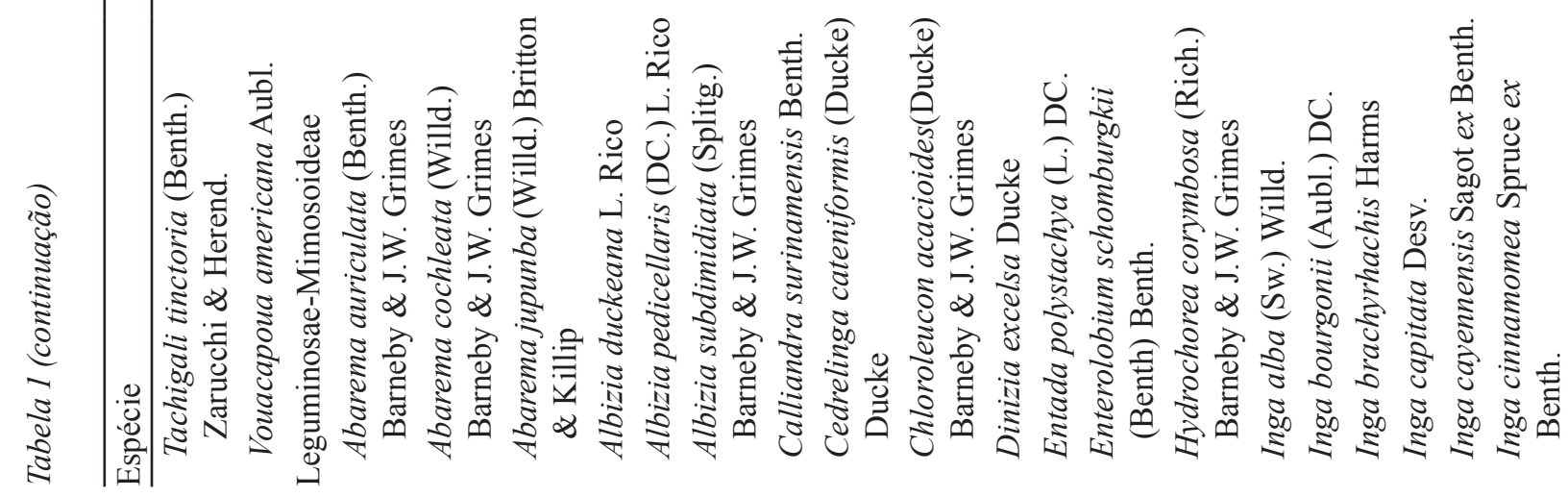




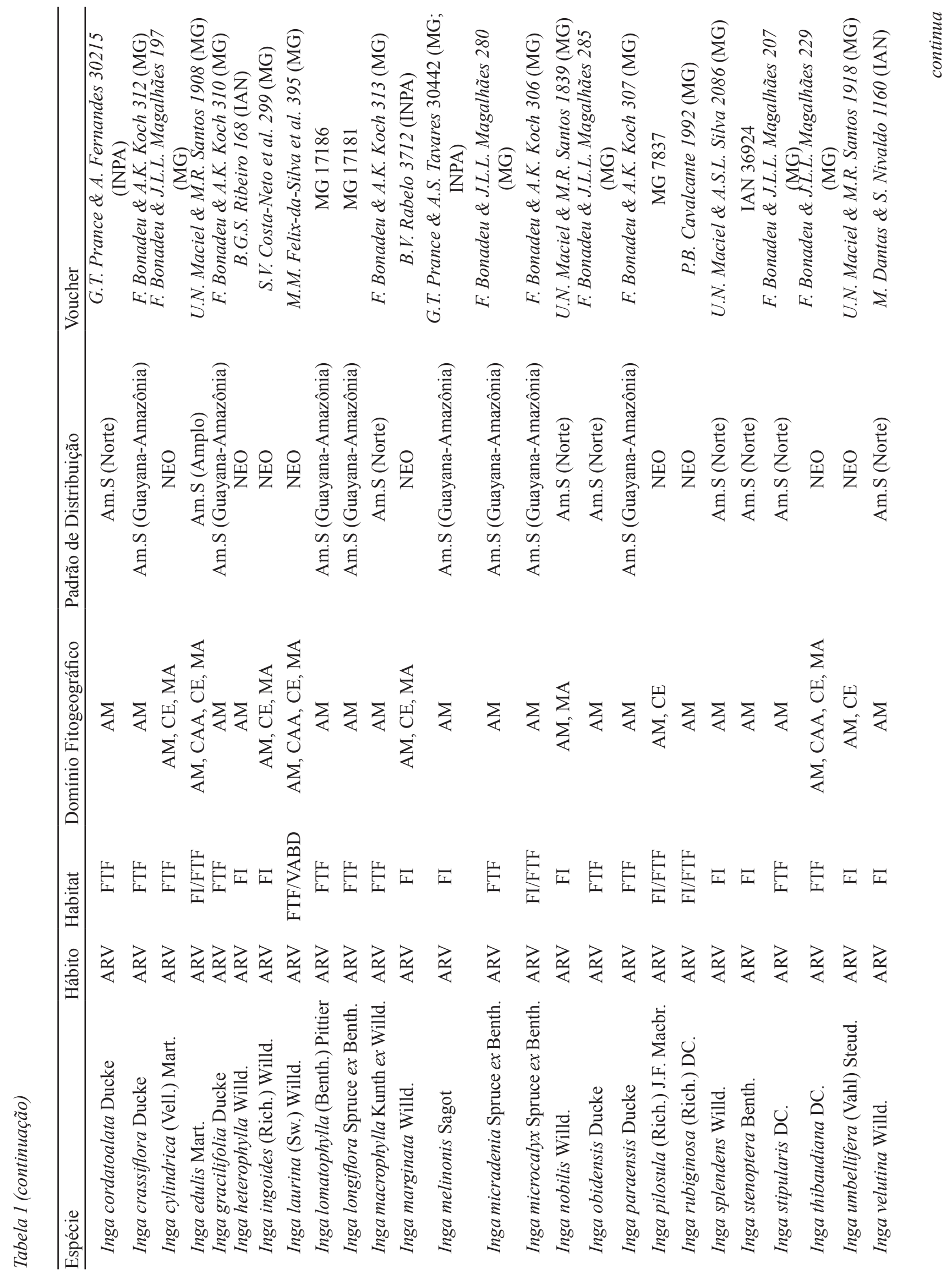




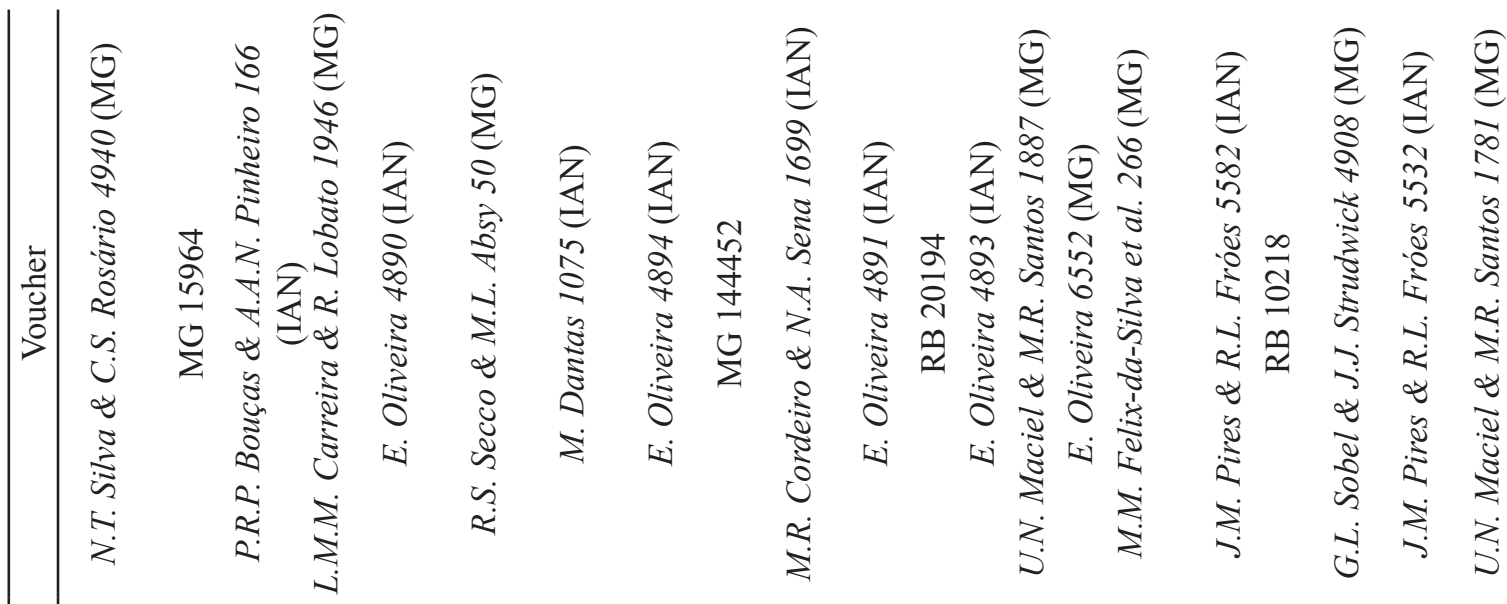

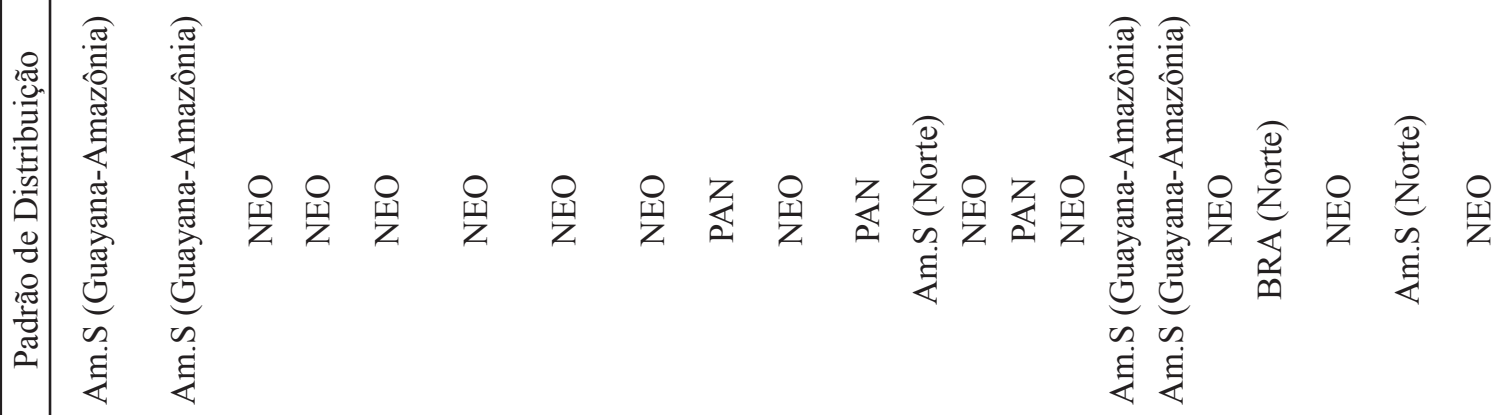

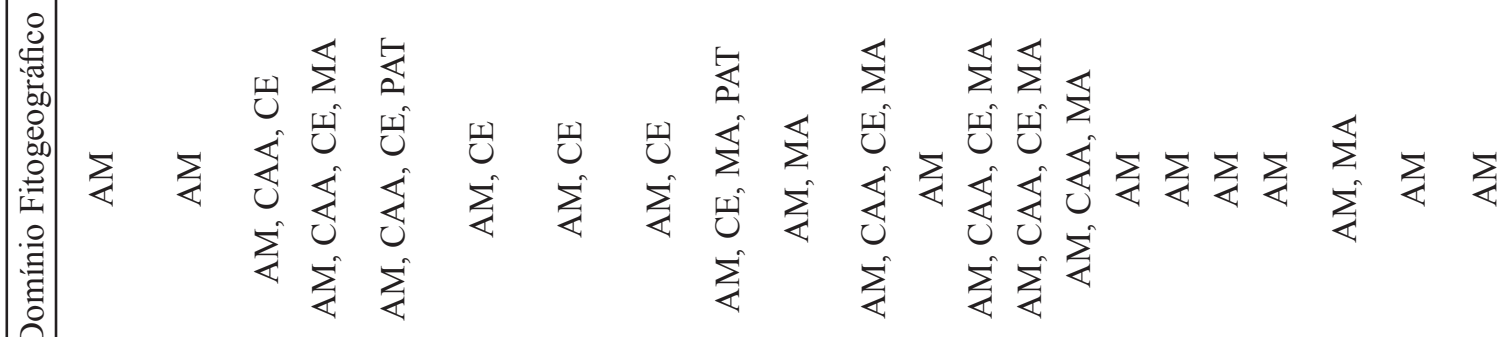

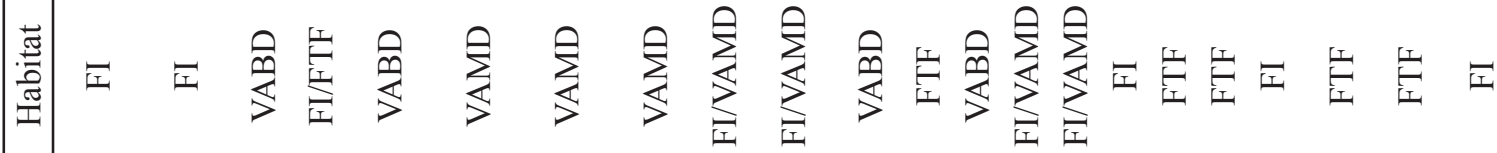

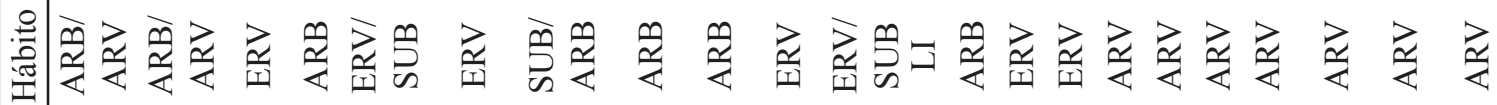

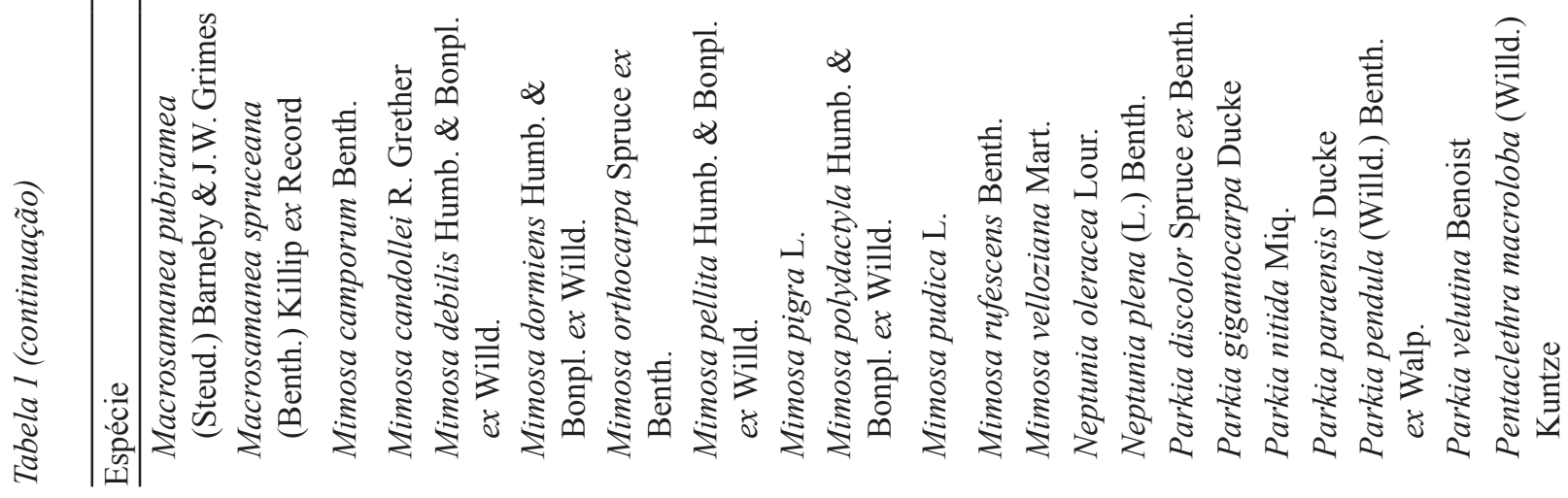




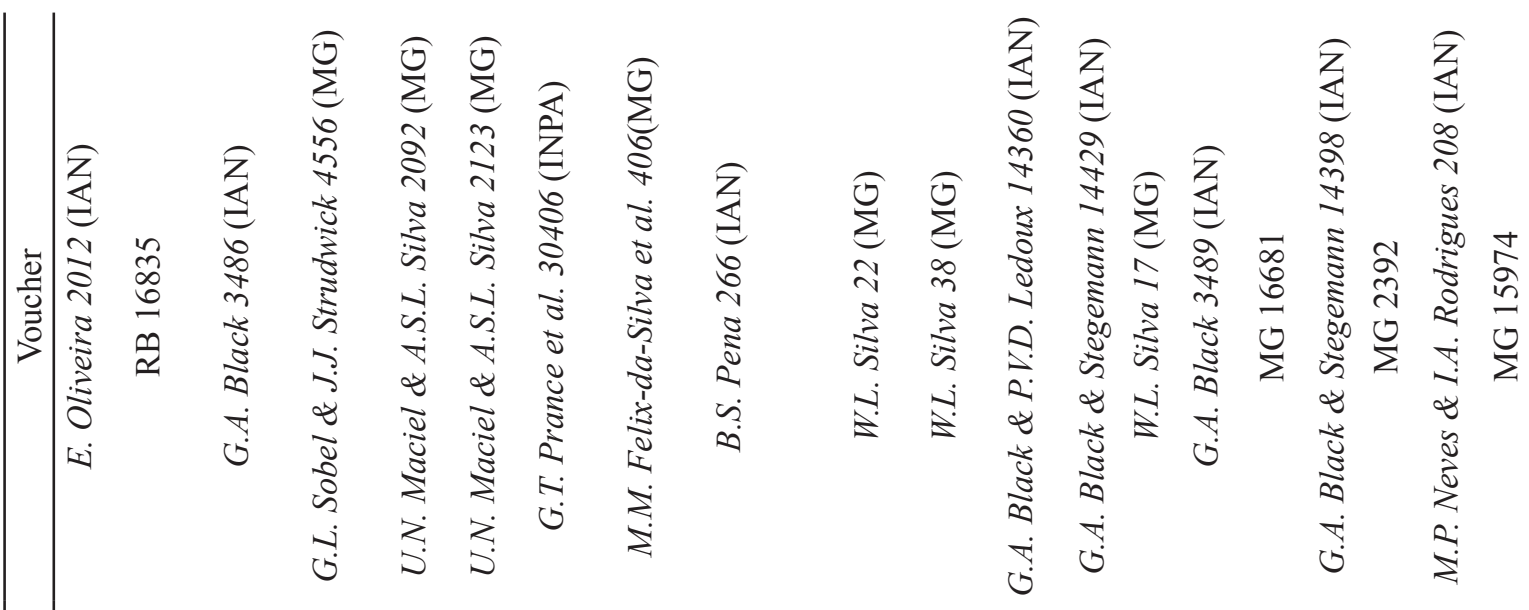

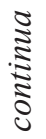

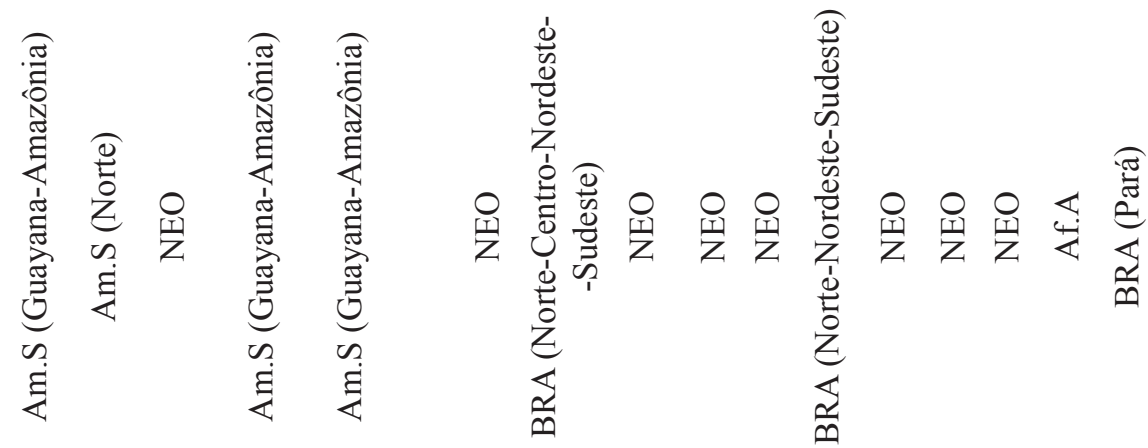

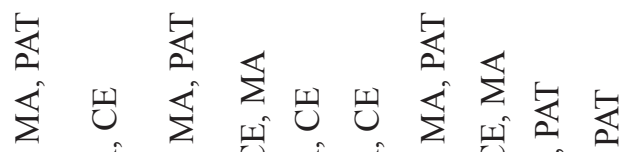
$\sum \sum_{i} \sum \sum \sum \sum \sum$

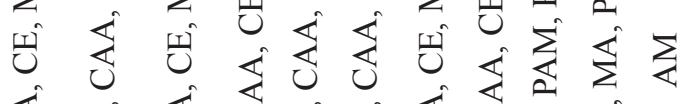

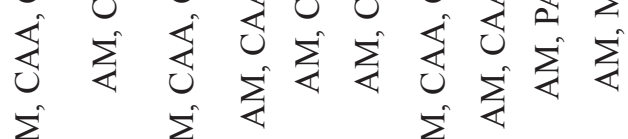

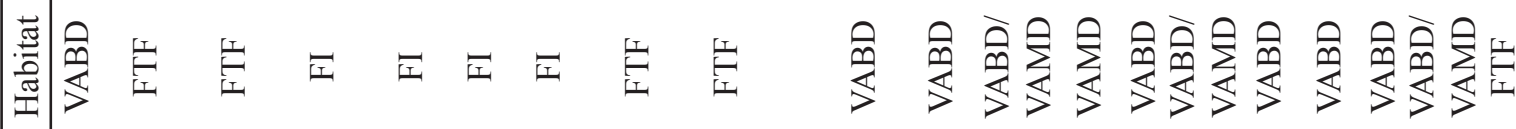

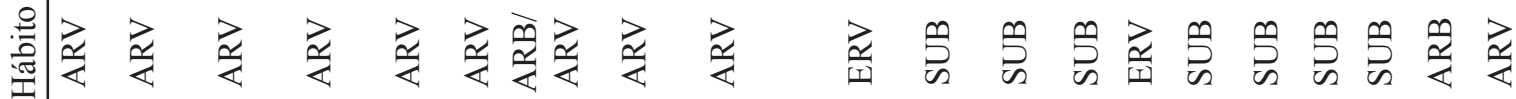

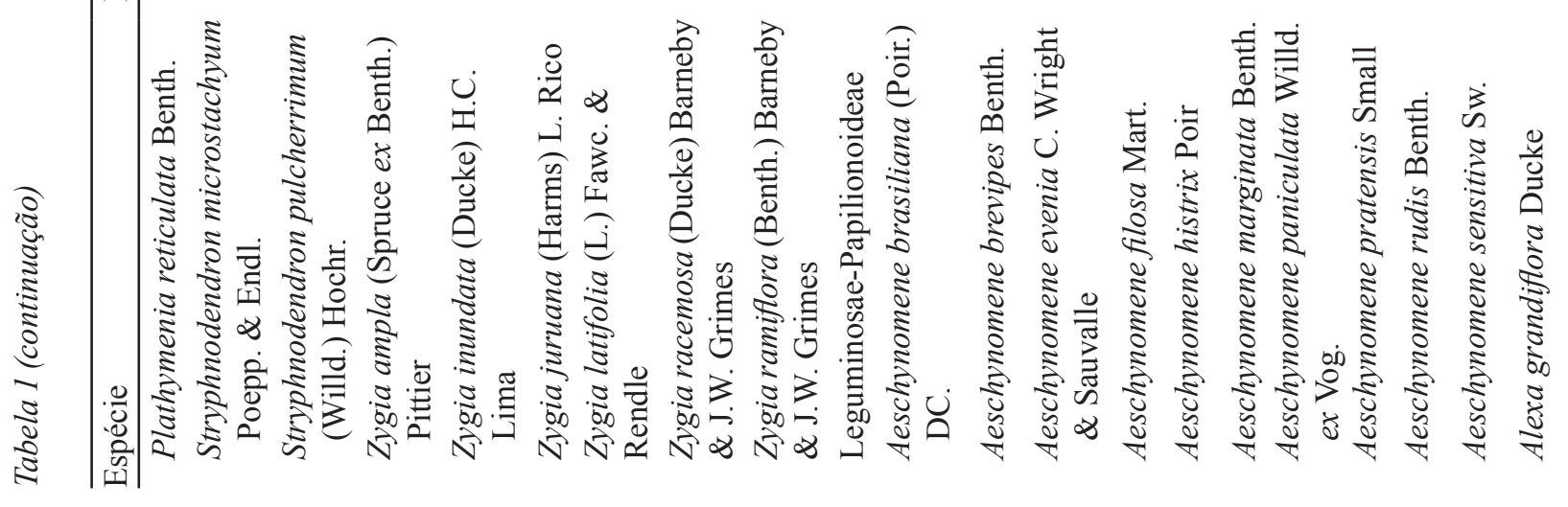




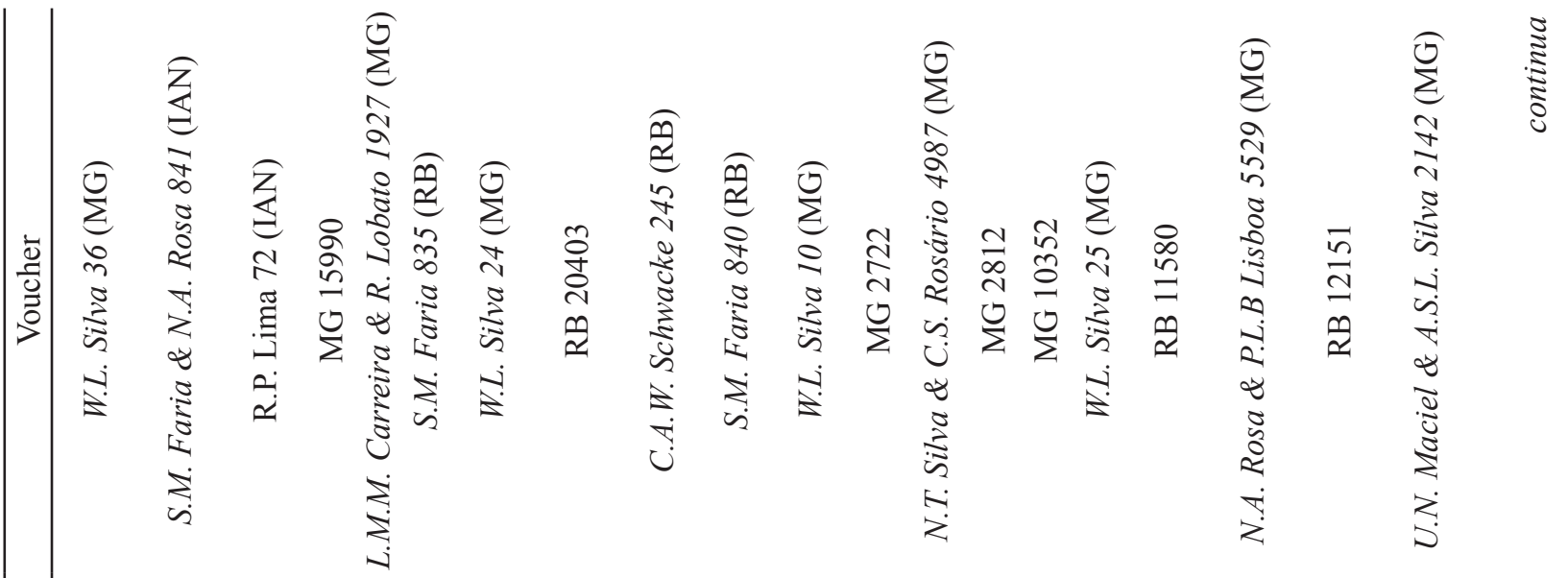

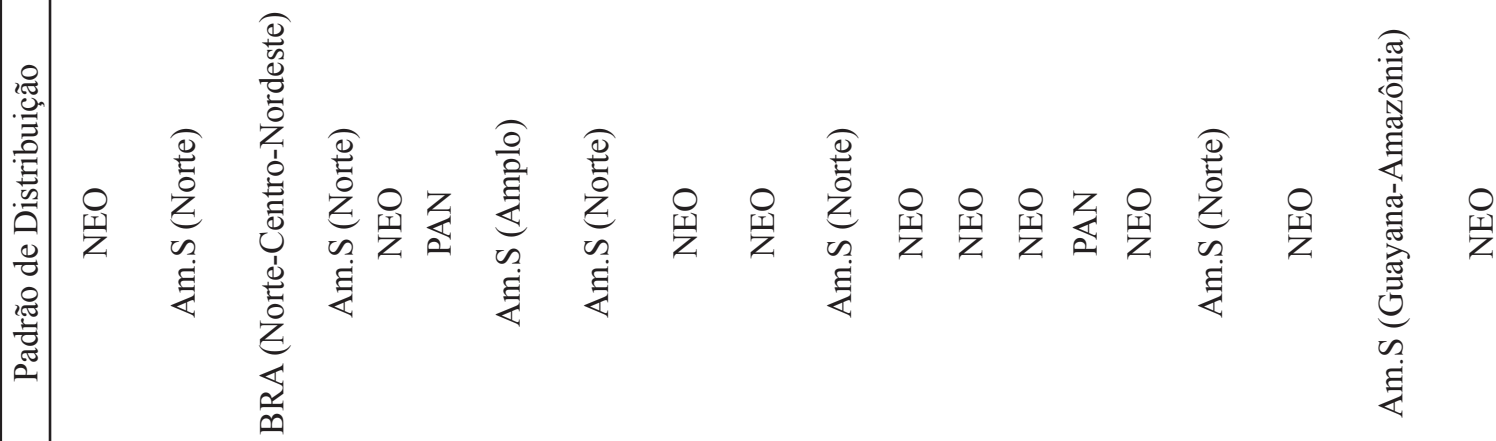

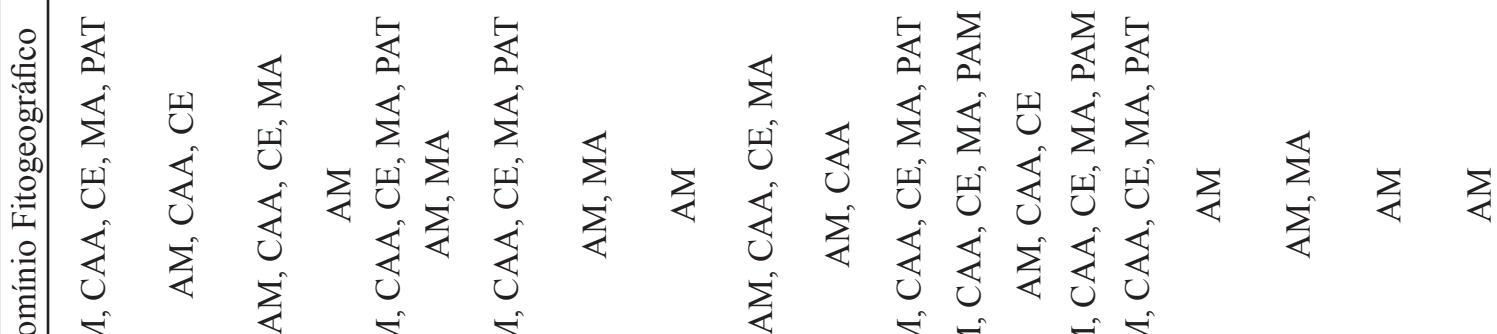

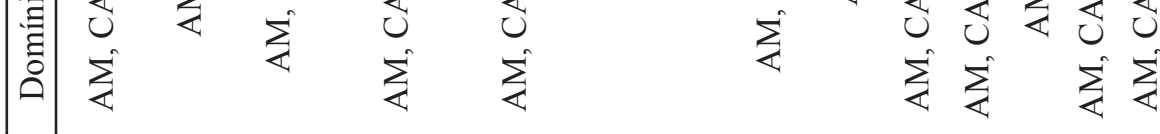

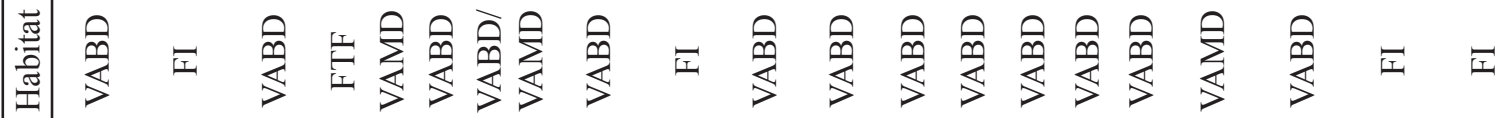

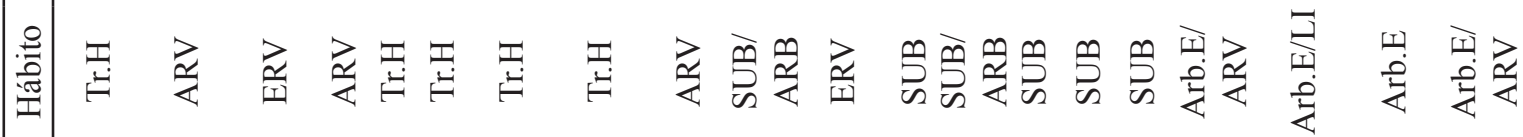

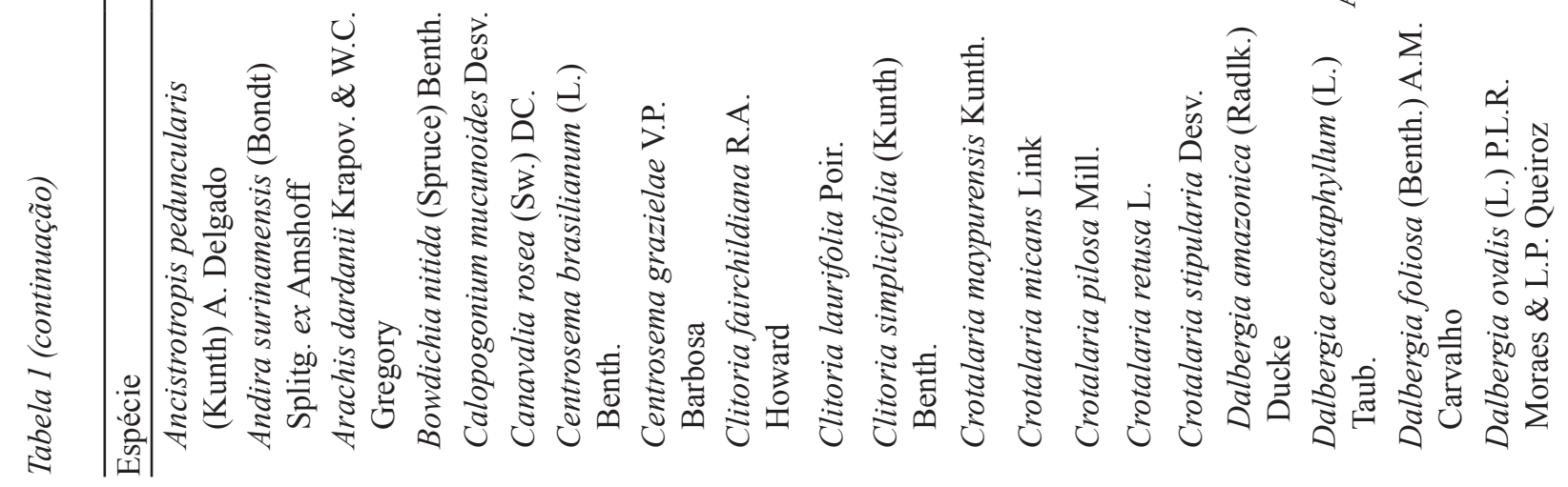




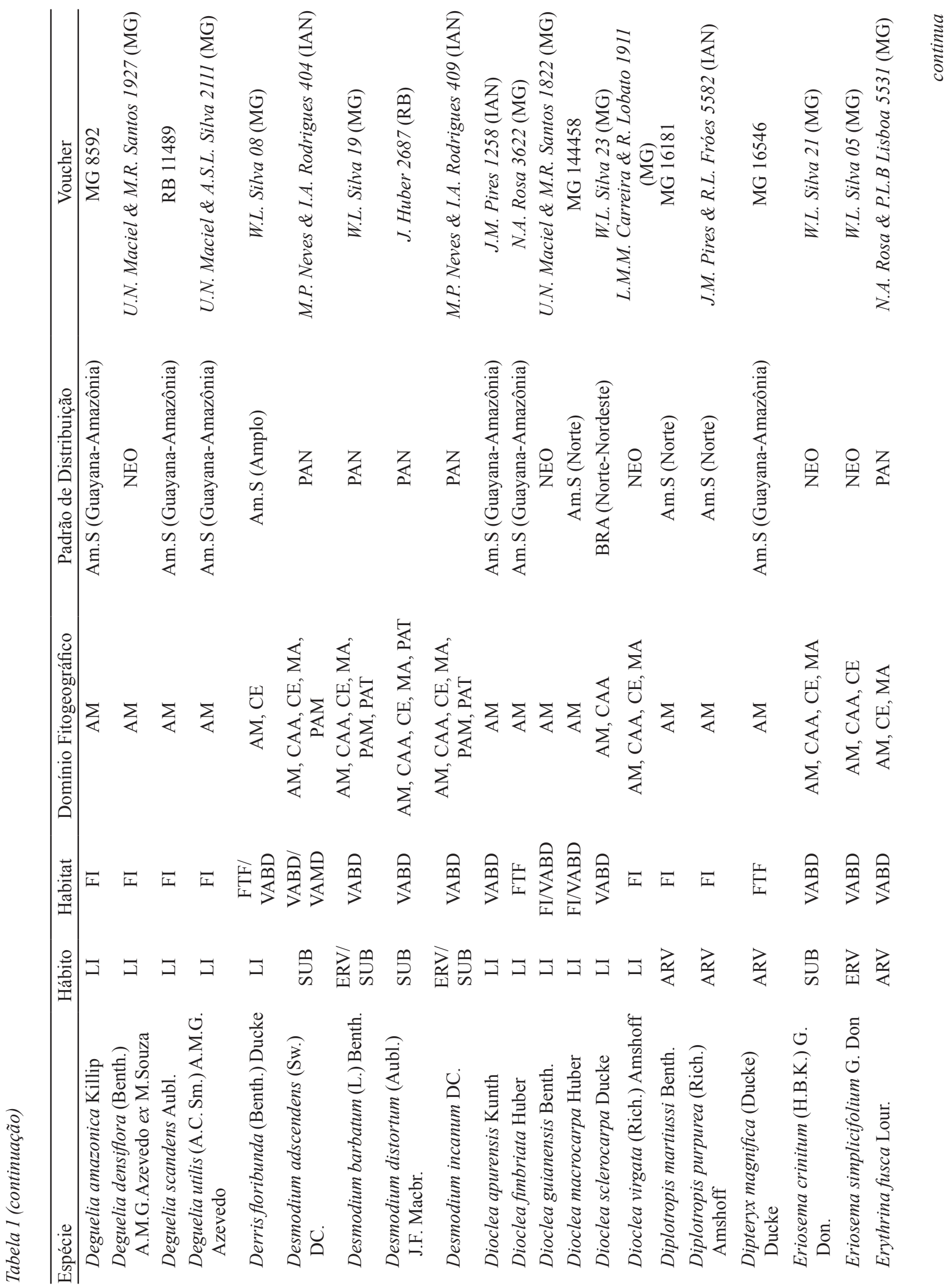




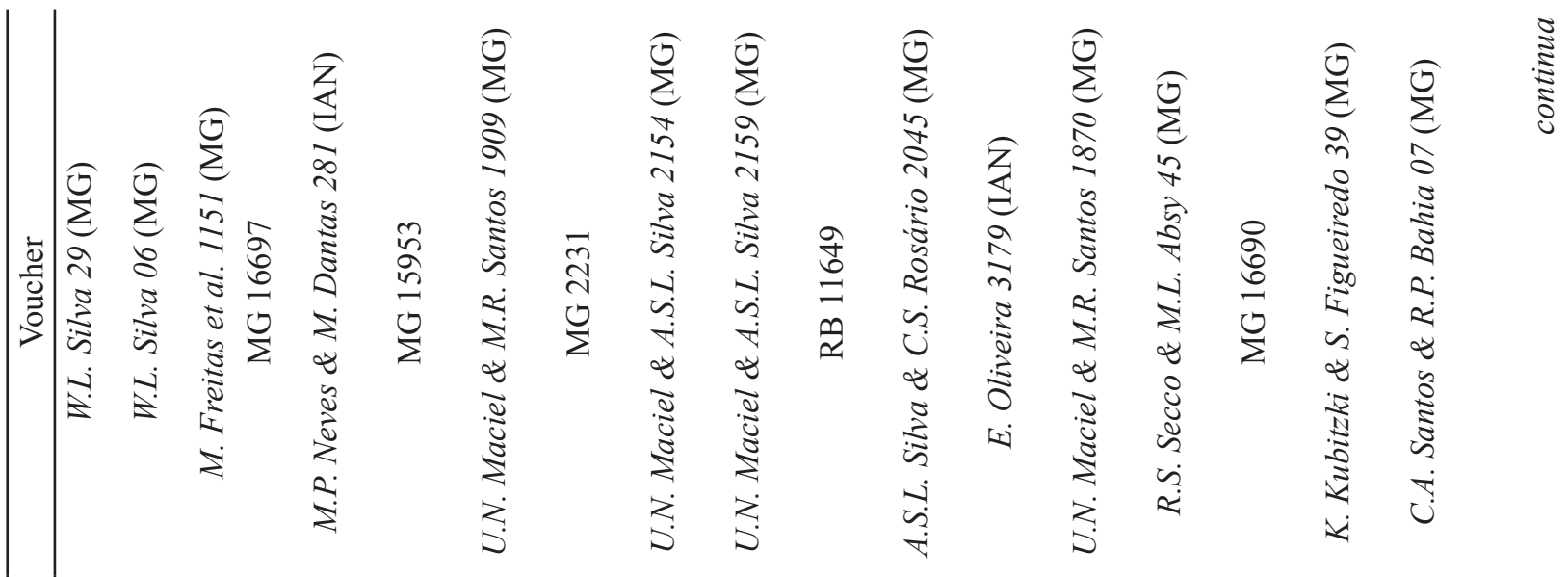

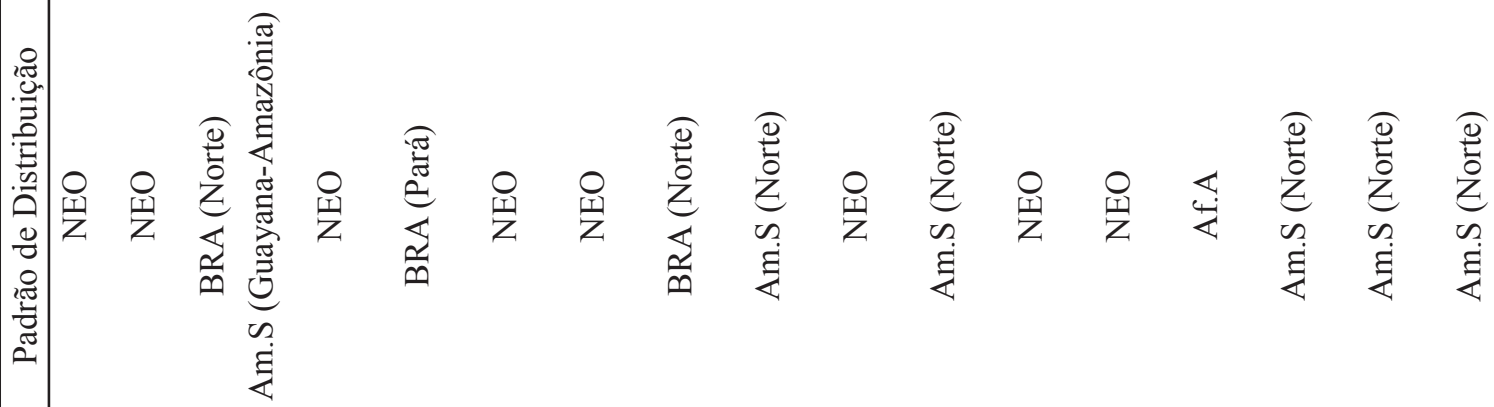

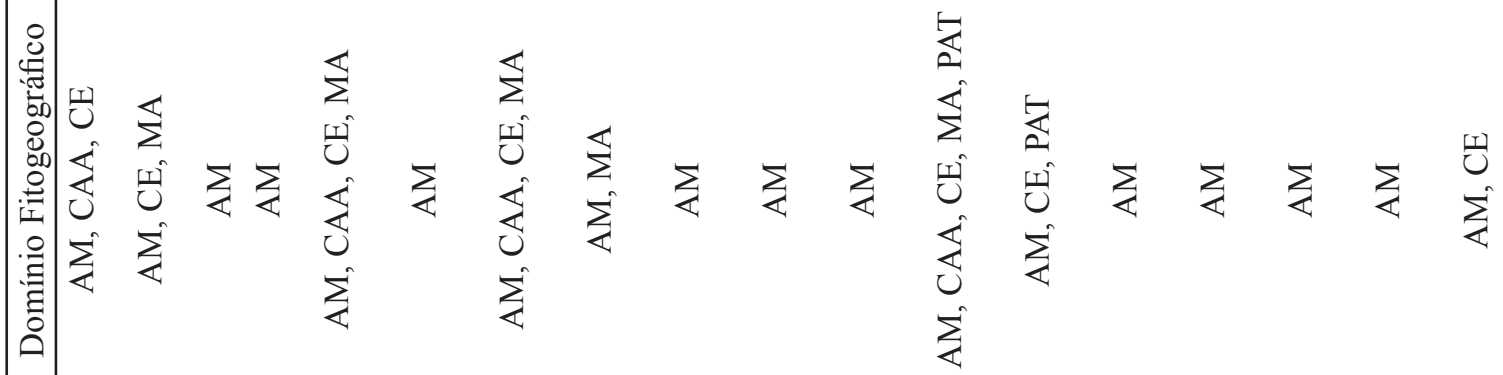

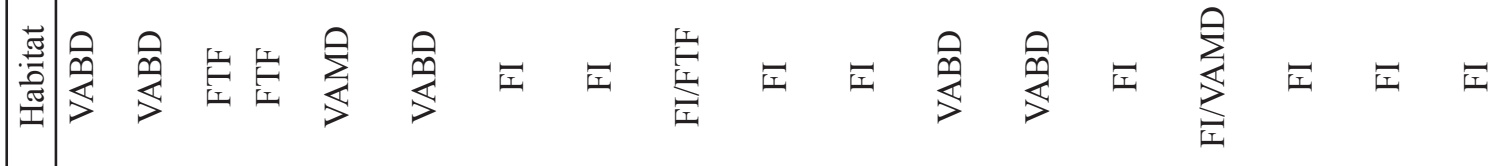

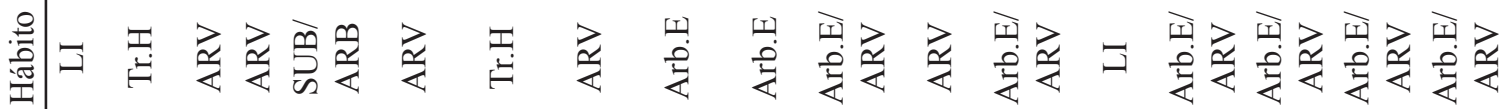

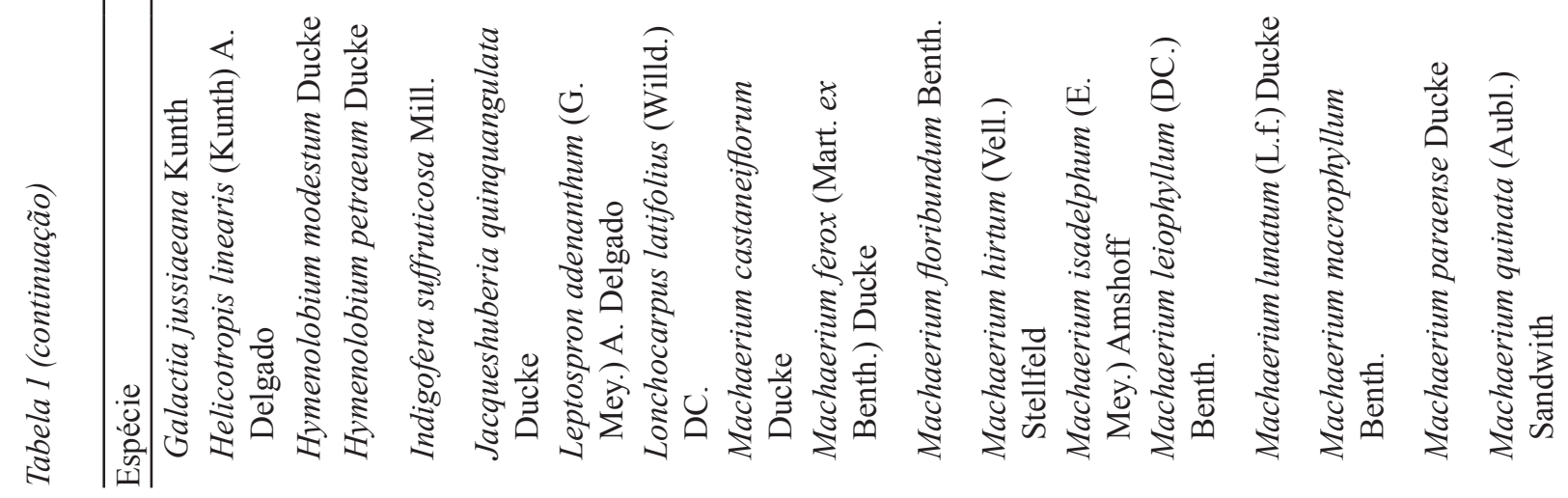




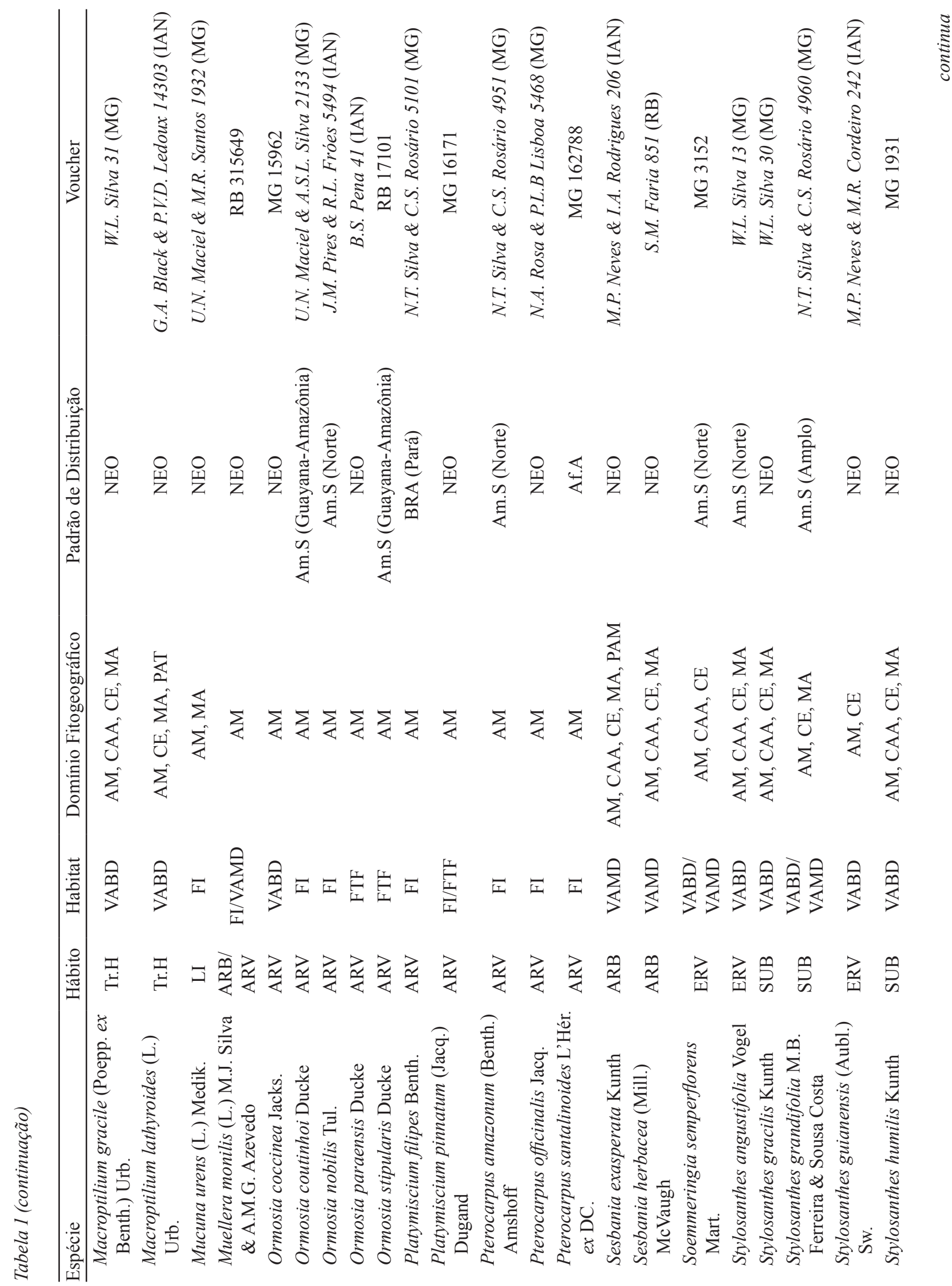




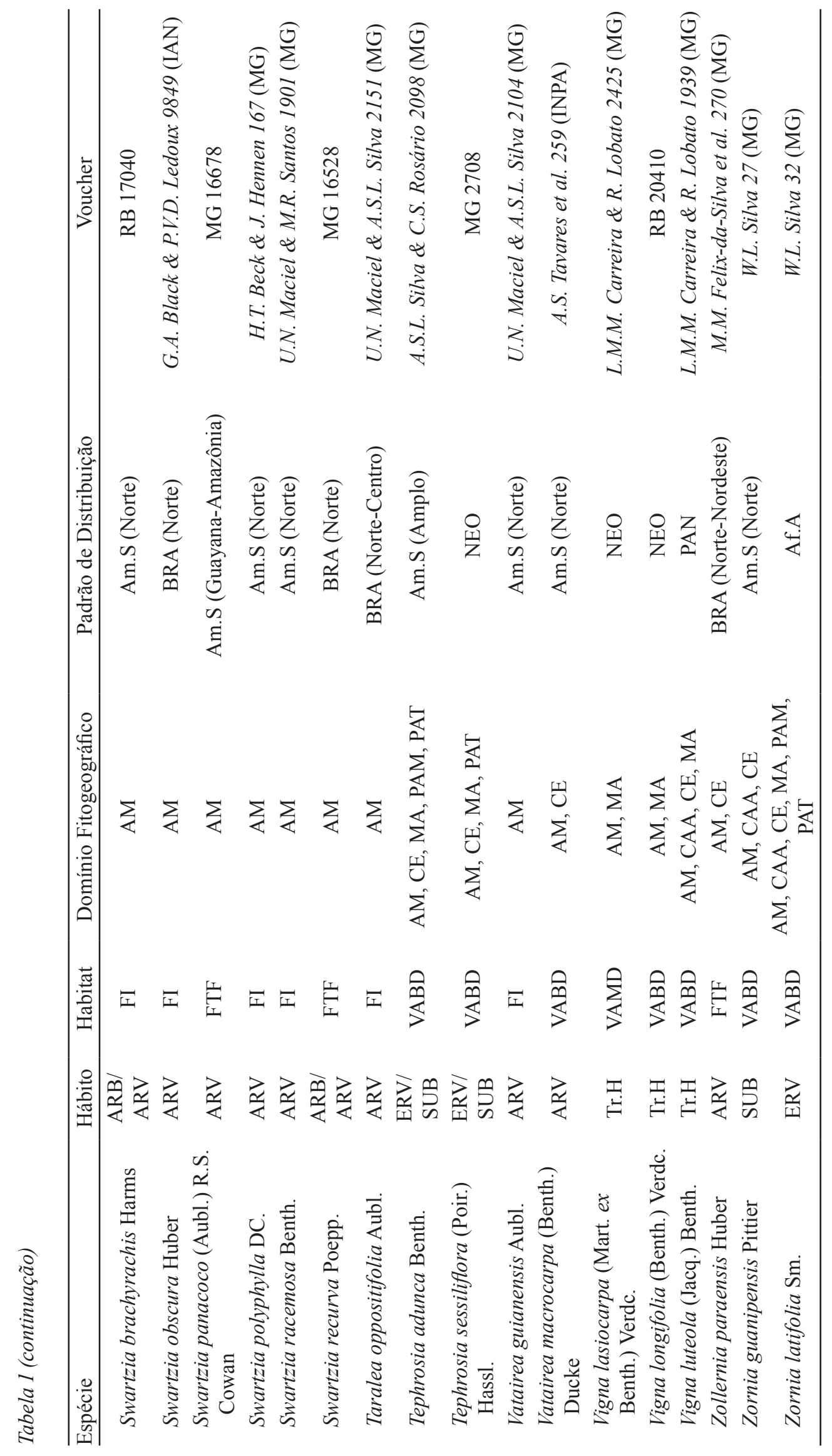


longo de formações abertas mal drenadas dos Estados da Bahia, Maranhão e Pará.

A coleção R.P. Lima 72 (IAN), de Arachis dardanii, foi citada com dúvidas por Krapovickas \& Gregory (1994) para a ilha de Marajó, mas sua identidade foi aqui confirmada com base na presença de pecíolo e raque canaliculados de forma contínua e face foliar abaxialmente glabra, características que permitem diagnosticá-la como tal.

Mesmo apresentando distribuição limitada ao norte da América do Sul, entre a Guiana Francesa, Venezuela e Brasil (Bahia, Maranhão, Pará, Pernambuco e Maranhão), segundo Aymard et al. (1999) e Perez (2012), a análise das coleções de Zornia guanipensis Pittier, depositadas nos herbários visitados, mostrou que, para o Estado do Pará, as populações desta espécie são restritas às savanas da ilha de Marajó, o que pode indicar a região como possível corredor biogeográfico entre as populações das regiões do escudo das Guianas com as da Caatinga e do Cerrado brasileiros.

A distribuição geográfica das espécies registradas para o arquipélago abrange cinco macrorregiões: 1) Anfiatlântico (Af.A), com quatro espécies $(1,6 \%)$; 2) América do Sul (Am.S), com 114 espécies (47,3\%); 3) Brasileiro (BRA), com 23 espécies $(9,5 \%)$; 4) Neotropical (NEO), com 85 espécies $(35,3 \%)$ e 5) Pantropical (PAN), com 15 espécies $(6,2 \%)$ (tabela 1).

Para as espécies de ocorrência restrita à América do Sul, exceto as endêmicas do Brasil, os seguintes padrões de distribuição foram estabelecidos: 1) distribuição ampla na América do Sul (Am.S Amplo), com 12 espécies (10,5\%); 2) distribuição de acordo com a bacia amazônica e extensões fitogeográficas do escudo das Guianas (Am.S Norte), com 66 espécies $(57,9 \%)$ e 3$)$ distribuição restrita à região fitogeográfica do escudo das Guianas e norte amazônico brasileiro (Am.S Guianas-Amazônia), com 36 espécies (31,6\%) (tabela 1$)$.

Entre as 23 espécies endêmicas do Brasil, os seguintes padrões de distribuição foram estabelecidos: 1) Brasil Norte, 11 espécies; 2) Brasil Norte-Centro, apenas uma espécie; 3) Brasil Norte-Centro-Nordeste, duas espécies; 4) Brasil Norte-Nordeste, quatro espécies; 5) Brasil Norte-Nordeste-Sudeste, apenas uma espécie; 6) Brasil Norte-Centro-NordesteSudeste, apenas uma espécie, e 7) Brasil-Pará, três espécies.
Em relação à distribuição fitogeográfica no Brasil, do total de espécies registradas no presente estudo, 125 (51,9\%) são exclusivas do domínio da Amazônia; dentre as restantes, a ocorrência amazônica é associada a outros domínios brasileiros, com destaque para o Cerrado (94 espécies), Mata Atlântica (81) e Caatinga (71). Apenas três espécies são citadas para os seis domínios brasileiros, Desmodium barbatum (L.) Benth., Desmodium incanum DC. e Zornia latifolia Sm., espécies amplamente distribuídas e comumente associadas às fisionomias campestres e áreas degradadas (Nobre et al. 2008, Perez 2009).

A contribuição principal de espécies associadas entre os domínios fitogeográficos Amazônia e restante do Brasil, como Cerrado e Caatinga, é oriunda dos gêneros Aeschynomene, Chamaecrista, Mimosa e Senna, de forma geral registrados no estudo em formações não florestais, com representantes de hábito principalmente herbáceo ou subarbustivo, amplamente distribuídos nos trópicos (Queiroz 2006, Mendonça et al. 2008). Em formações florestais, o gênero Inga foi um dos principais, com espécies amazônicas e da Mata Atlântica, representado predominantemente pelas espécies neotropicais (Pennington 1997).

A sobreposição na distribuição de espécies, entre regiões fitogeográficas brasileiras, também foi constatada nas floras da Amazônia, Mata Atlântica e Cerrado (Méio et al. 2003). Assim, Andrade-Lima (1966), Mori et al. (1981), Prance (1982) e Cavalcanti \& Tabarelli (2004) sugeriram que a ocorrência de espécies com padrões disjuntos de distribuição, entre Amazônia e Mata Atlântica, indicariam a possibilidade de conexão no passado entre as floras dessas regiões através do bioma cerrado, como observado na distribuição geográfica de algumas espécies registradas no presente estudo, como Inga nobilis Willd., Cedrelinga cateniformis (Ducke) Ducke e Diplotropis purpurea (Rich.) Amshoff.

De modo geral, as fitofisionomias florestais apresentaram maior número de Leguminosae exclusivas (143 espécies), predominantemente arbóreas, destacando-se as vegetações inundáveis, com 80 espécies, enquanto nas vegetações florestais de terra firme, foram registradas 48 , sendo a família com maior riqueza nesses ambientes (Campbell et al. 1986, Oliveira 2000, Almeida et al. 2004, Carim et al. 2008). As fitofisionomias não florestais foram representadas, predominantemente, por membros não arbóreos de Papilionoideae (52 espécies), subfamília registrada como a mais rica nesses ambientes amazônicos (Secco 
\& Mesquita 1983, Bastos 1984, Miranda \& Absy 2000), com destaque para os gêneros Aeschynomene e Crotalaria, como também registrado por Flores \& Rodrigues (2010) e Caboco et al. (2012). Formações vegetacionais abertas e bem drenadas apresentaram 61 espécies exclusivas, principalmente ervas e subarbustos; em contrapartida, formações abertas, mal drenadas, registraram menor riqueza, 13 espécies, principalmente arbóreas, arbustivas ou subarbustivas, característica comum para a família nesse tipo de ambiente (Tannus \& Assis 2004, Munhoz \& Felfili 2008, Rossato et al. 2008).

Levando-se em consideração as espécies que ocorreram em formações não florestais, principalmente savanas e campos alagados da região leste do Marajó, nota-se o predomínio daquelas Neotropicais ou Pantropicais (cerca de 70\%), característica que se assemelha aos resultados de Flores \& Rodrigues (2010) para áreas de savana e mata ciliar de Roraima. Contudo diferem dos resultados registrados para regiões da Caatinga e Cerrado, onde o número de espécies amplamente distribuídas é reduzido (Queiroz 2006, Filardi et al. 2007). Comprova-se, dessa forma, o baixo endemismo citado por Ducke \& Black (1954) e Pires (1973) para a região e por De Granville (1982) para savanas da Guiana Francesa, adjacentes à área de estudo. O baixo número de espécies endêmicas também é ocorrente em outros grupos biológicos para a região (Henriques \& Oren 1997), resultado possivelmente oriundo da formação geológica recente do arquipélago de Marajó (Rossetti et al. 2010).

As espécies restritas à Amazônia brasileira ocorreram principalmente nas formações florestais, sendo sete Caesalpinioideae [Eperua duckeana Cowan, Macrolobium brevense Ducke, Mora paraensis Ducke, Phanera confertiflora (Benth.) Vaz, P. platycalyx (Benth.) Vaz, P. rutilans (Spruce ex Benth.) Vaz e Tachigali goeldiana (Huber) L.G.Silva \& H.C.Lima]; duas Mimosoideae [Abarema cochleata (Willd.) Barneby \& J.W. Grimes e Parkia paraensis Ducke]; e sete Papilionoideae [Alexa grandiflora Ducke, Hymenolobium modestum Ducke, Jacqueshuberia quinquangulata Ducke, Platymiscium filipes Benth., Swartzia recurva Poepp., S. obscura Huber e Taralea oppositifolia Aubl.].

Jacqueshuberia quinquangulata apresenta populações restritas a uma reduzida área de campina mal drenada do município de Gurupá (Silva \& Graham 1980), caracterizando seu estado de conservação como "em perigo", segundo IUCN (2010), entretanto, frente a iminente exploração econômica e possível perda de habitat na região, poderá ser conduzida a categoria de planta extinta.

Platymiscium filipes e Alexa grandiflora são endêmicas do Estado do Pará, a primeira é restrita às florestas inundáveis ou margens de rios com influência marinha, classificada por Klitgaard (2005) como "vulnerável", em decorrência de perdas populacionais. Alexa grandiflora é restrita às vegetações ciliares inundáveis ou não inundáveis de diferentes regiões do Estado do Pará (Ducke 1949, Ramirez 1995). Apesar de Parkia gigantocarpa Ducke não apresentar voucher, Ducke (1949) citou sua ocorrência para áreas de floresta de terra firme nos municípios de Breves e Gurupá, assim como também mencionado por Hopkins (1986).

Em conclusão, embora este estudo mostre números significativos em relação às Leguminosae registradas para o Estado do Pará, estes podem estar subestimados, pois a grande extensão geográfica do arquipélago de Marajó, somada a insuficiência amostral de coletas em algumas regiões, ressaltam a necessidade de se intensificar expedições em determinados pontos do arquipélago, cobrindo ainda mais as diferentes tipologias vegetacionais e expandindo dessa forma as coleções botânicas da região.

\section{Agradecimentos}

Ao Ministério da Ciência, Tecnologia e Inovação, através do Programa de Capacitação Institucional (PCI), pela bolsa concedida ao primeiro Autor ao Museu Paraense Emílio Goeldi (MPEG), pelo apoio logístico. Ao técnico Dr. Antônio Elielson Sousa da Rocha, do Herbário João Murça Pires (MG) - Museu Paraense Emílio Goeldi, pelas críticas e sugestões do manuscrito.

\section{Literatura citada}

Almeida, S.S., Amaral, D.D. \& Silva, A.S. 2004. Análise florística e estrutura de florestas de várzea no estuário amazônico. Acta Amazonica 34: 513-524.

Almeida, S.S., Lisboa, P.L.B. \& Silva, A.S.L. 1993. Diversidade florística de uma comunidade arbórea na Estação científica "Ferreira Penna", em Caxiuanã (Pará). Boletim do Museu Paraense Emílio Goeldi - Série Botânica 9: 93-128. 
Amaral, D.D., Vieira, I.C.G., Salomão, R.P., Almeida, S.S., Silva, J.B.F., Costa Neto, S.V., Santos, J.U.M., Carreira, L.M.M. \& Bastos, M.N.C. 2007. Campos e florestas das bacias dos rios Atuá e Anajás, Ilha de Marajó. Belém. Museu Paraense Emílio Goeldi, Belém.

Andrade-Lima, D. 1966. Contribuição ao estudo do paralelismo da flora Amazônico-Nordestina. Boletim Técnico do Instituto de Pesquisa Agronômicas de Pernambuco 19: 1-30.

Aymard, G.A., Cuello, N.L., Berry, P.E., Rudd, V.E., Cowan, R.S., Fantz, P.R., Maxwell, R.H., Stirton, C.H., Poppendieck, H., Lima, H.C., Fortunato, R.H., Stergios, B., Enrich, N.X., Neill, D.A., Pennington, R.T. \& Gil, C. 1999. Fabaceae. In: P.E. Berry, K. Yatskievych \& B.K. Holst (eds.). Flora of the Venezuelan Guayana. Eriocaulaceae-Lentibulariaceae. Missouri Botanical Garden Press, St. Louis, v.5, pp. 231-433.

Barneby, R.C., Grimes, J.W., Berry, P.E., Brunner, D., Forero, E., Cárdenas, L., Martino, G., Hopkins, H.C.F. \& Occhioni, E.M.L. 2001. Mimosaceae. In: P.E. Berry, K. Yatskievych \& B.K. Holst (eds.). Flora of the Venezuelan Guayana. Liliaceae-Myrsinaceae. Missouri Botanical Garden Press, St. Louis, v.6, pp. 580-686.

Barneby, R.C., Stergios, B., Cowan, R.S., Berry, P.E., Zarucchi, J.L., Wunderlin, R.P., Kearns, D.M., Silva, M.F., Tavares, A.S., Velásquez, D., Xena, N. \& Aymard, G.A. 1998. Caesalpiniaceae. In: P.E. Berry, K. Yatskievych \& B.K. Holst (eds.). Flora of the Venezuelan Guayana. Caesalpiniaceae-Ericaceae. Missouri Botanical Garden Press, St. Louis, v.4, pp. 1-121.

Bastos, M.N.C. 1984. Levantamento florístico dos campos do Estado do Pará. I - Campos de Joanes, Ilha de MarajóPará. Boletim do Museu Paraense Emílio Goeldi - Série Botânica 1: 67-86.

Bastos, M.N.C. 1987. Contribuição ao estudo de algumas espécies do gênero Machaerium Persoon (Leguminosae-Papilionoideae), ocorrentes na Amazônia brasileira. Boletim do Museu Paraense de História Natural 3: 183-278.

Boggan, J., Funk, V., Kelloff, C., Hoff, M., Cremers, G. \& Feuillet, C. 1997. Checklist of the plants of the Guianas. Smithsonian Institution, University of Guyana, Georgetown.

Bove, C.P., Gil, A.S.B., Moreira, C.B. \& Anjos, R.F.B. 2003. Hidrófitas fanerogâmicas de ecossistemas aquáticos temporários da Planície Costeira do estado do Rio de Janeiro, Brasil. Acta Botanica Brasilica 17: 119-135.

Caboco, R.B., Rolim, T.P., Sartori, Â.L.B. \& Sciamarelli, A. 2012. Leguminosae-papilionoideae from the parque estadual das Várzeas do Rio Ivinhema, Mato Grosso do Sul State, Brazil. Biota Neotropica 12. http://www.biotaneotropica.org.br/v12n1/ en/abstract?article+bn01212022012 (acesso em 22.10.2012).
Campbell, D.G., Daly, D.C., Prance, G.T. \& Maciel, U.N. 1986. Quantitative ecological inventory of terra firme and várzea tropical forest on the Rio Xingú, Brazilian Amazonia. Brittonia 38: 369-393.

Capobianco, J.P.R., Veríssímo, A., Moreira, A., Sawyer, D., Santos, I. \& Pinto, L.P. 2001. Biodiversidade na Amazônia brasileira. Estação Liberdade, Instituto Socioambiental, São Paulo.

Carim, M.J.V., Jardim, M.A.G. \& Medeiros, T.D.S. 2008. Composição floristica e estrutura de floresta de várzea no município de Mazagão, Estado do Amapá, Brasil. Scientiae Forestalis 36: 191-201.

Cavalcanti, D. \& Tabarelli, M. 2004. Distribuição das plantas Amazônico-Nordestinas no Centro de Endemismo Pernambuco: Brejos de Altitude vs. Floresta de Terras Baixas. In: K.C. Pôrto, J.J.P. Cabral \& M. Tabarelli (eds.). Brejos de Altitude em Pernambuco e Paraíba. Ministério do Meio Ambiente, Brasília, pp. 285-296.

De Granville J.J. 1982. Rain forest and xeric flora refuges in French Guiana. In: G.T. Prance (ed.). Biological diversification in the tropics. Columbia University Press, New York, pp. 159-181.

Dias, S.F. 1973. Classificação de vegetação e floresta recomendada para a ilha de Marajó. IDESP, Belém.

Ducke, A. \& Black, G.A. 1954. Notas sobre a fitogeografia da Amazônia brasileira. Boletim Técnico do Instituto Agronômico do Norte 29: 3-48.

Ducke, A. 1922. Plantes nouvelles ou peu connues de la région amazonienne II. Archivos do Jardim Botânico do Rio de Janeiro 3: 161-162.

Ducke, A. 1925. As leguminosas do estado Pará. Archivos do Jardim Botanico do Rio de Janeiro 4: 211-341.

Ducke, A. 1939. As leguminosas da Amazônia brasileira. Serviço Florestal do Ministério da Agricultura, Rio de Janeiro.

Ducke, A. 1944. New or noteworthy Leguminosae on the Brasilian Amazonian. Boletim Técnico do Instituto Agronômico do Norte 2: 1-33.

Ducke, A. 1946. Plantas de cultura pré-colombiana na Amazônia Brasileira: notas sobre as espécies ou formas espontâneas que supostamente lhes teriam dado origem. Boletim Técnico do Instituto Agronômico do Norte 8: 3-24.

Ducke, A. 1949. Notas sobre a flora neotropica II. As Leguminosas da Amazônia Brasileira. Boletim Técnico do Instituto Agronômico do Norte 18: 1-248.

Farruggia, F.T. 2009. Phylogenetic and monographic studies of the Pantropical genus Sesbania Adanson (Leguminosae). Tese de Doutorado, Arizona State University, Arizona.

Ferreira, L.V. \& Prance, G.T. 1998. Structure and species richness of low-diversity floodplain forest on the Rio Tapajós, Eastern Amazonia, Brazil. Biodiversity and Conservation 7: 585-596. 
Ferri, M.G., Menezes, N.L. \& Monteiro, W.R. 1981. Glossário ilustrado de Botânica. Nobel, São Paulo.

Filardi, F.L.R., Garcia, F.C.P., Dutra, V.F. \& São-Thiago, P.S. 2007. Papilionoideae (Leguminosae) do Parque Nacional da Serra da Canastra, Minas Gerais, Brasil. Hoehnea 34: 383-408.

Filgueiras, T.S., Nogueira, P.E., Brochado, A.L. \& Guala II, G.F. 1994. Caminhamento: um método expedito para levantamentos florísticos qualitativos. Cadernos de Geociências 12: 39-43.

Flores, A.S. \& Rodrigues, R.S. 2010. Diversidade de Leguminosae em uma área de savana do estado de Roraima, Brasil. Acta Botanica Brasilica 24: 175-183.

Funk, V., Hollowell, T., Berry, P., Kelloff, C. \& Alexander, N.S. 2007. Checklist of the plants of the Guiana Shield (Venezuela: Amazonas, Bolivar, Delta Amacuro; Guyana, Surinam, French Guiana). Contributions from the United States National Herbarium 55: 1-584.

Gentry, A.H. 1988. Changes in plant community diversity and floristic composition on environmental and geographical gradients. Annals of the Missouri Botanic Garden 75: 1-34.

Henriques, L.M.P. \& Oren, D.C. 1997. The avifauna of Marajó, Caviana and Mexiana islands, Amazon River estuary, Brazil. Revista Brasileira Biologia 57: 357-382.

Hopkins, H.C.F. 1986. Parkia (Leguminosae: Mimosoideae). Flora Neotropica 43. New York Botanical Garden, New York.

Hopkins, M.J.G. 2005. Flora da Reserva Ducke, Amazonas, Brasil. Rodriguésia 56: 9-25.

Huber, J. 1898. Materiais para a Flora Amazônica. I. Lista das plantas coligidas da Ilha de Marajó no ano de 1896. Boletim do Museu Paraense Emílio Goeldi 1-4: 288-322.

Huber, J. 1902. Materiais para a Flora Amazônica. V. Plantas Vasculares colhidas ou observadas na região dos furos de Breves em 1900 e 1901. Boletim do Museu Paraense Emílio Goeldi 3: 400-406.

Huber, J. 1943. Contribuição à geografia física dos furos de Breves e da parte ocidental de Marajó. Revista Brasileira de Geografia 5: 129-154.

IBGE. 2012. Manual Técnico da Vegetação Brasileira. Série Manuais Técnicos em Geociências 1, $2^{\mathrm{a}}$ edição revista e ampliada. IBGE, Rio de Janeiro.

INMET. 2012. Rede de Estações Climatológicas. Instituto Nacional de Metereologia. http://www.inmet. gov.br/portal/index.php?r=home/index (acesso em 12.08.2012).

IUCN. 2010. Guidelines for Using the IUCN Red List Categories and Criteria. 8.1. Prepared by the Standards and Petitions Working Group of the IUCN SSC Biodiversity Assessments Sub-Committee in 08-2010. http://intranet.iucn.org/webfiles/doc/SSC/RedList/ RedListGuidelines.pdf (acesso em 24.09.2012).
Kelloff, C.L. \& Funk, V.A. 2004. Phytogeography of the Kaieteur Falls, Potaro Plateau, Guyana: floral distributions and affinities. Journal of Biogeography 31: 501-513.

Kerr, J.T. 1997. Species richness, endemism, and the choice of areas for conservation. Conservation Biology 11: 1094-1100.

Klitgaard, B.B. 2005. Platymiscium (Leguminosae: Dalbergieae): biogeography, morphology, taxonomy and uses. Kew Bulletin 60: 321-400.

Krapovickas, A. \& Gregory, W.C. 1994. Taxonomía del género Arachis (Leguminosae). Bonplandia 8: 1-186.

Lewis, G.P. \& Owen, P.E. 1989. Legumes of the Ilha de Maracá. Royal Botanic Gardens, Kew.

Lewis, G.P., Schrire, B., Mackinder, B. \&. Lock, M. 2005. Legumes of the World. Royal Botanical Gardens, Kew.

Lima, H.C. de, Queiroz, L.P., Morim, M.P., Souza, V.C., Dutra, V.F., Bortoluzzi, R.L.C., Iganci, J.R.V., Fortunato, R.H., Vaz, A.M.S.F., Souza, E.R., Filardi, F.L.R., Valls, J.F.M., Garcia, F.C.P., Fernandes, J.M., Martins-da-Silva, R.C.V., Perez, A.P.F., Mansano, V.F., Miotto, S.T.S., Tozzi, A.M.G.A., Meireles, J.E., Lima, L.C.P. , Oliveira, M.L.A.A., Flores, A.S., Torke, B.M., Pinto, R.B., Lewis, G.P., Barros, M.J.F., Schütz, R., Pennington, T., Klitgaard, B.B., Rando, J.G., Scalon, V.R., Cardoso, D.B.O.S., Costa, L.C., Silva, M.J., Moura, T.M., Barros, L.A.V., Silva, M.C.R., Queiroz, R.T., Sartori, A.L.B. \& Camargo, R. 2012. Fabaceae. Lista de Espécies da Flora do Brasil. Jardim Botânico do Rio de Janeiro. http://floradobrasil. jbrj.gov.br/2012/FB000115 (acesso em 07.09.2012).

Méio, B.B., Freitas, C.V., Jatobá, L., Silva, M.E.F., Ribeiro, J.F. \& Henriques, R.P.B. 2003. Influência da flora das florestas Amazônicas e Atlânticas na vegetação do cerrado sensu stricto. Revista Brasileira de Botânica 26: 437-444.

Mendonça, R.C., Felfili, J.M., Walter, B.M.T., Silva Júnior, M.C., Rezende, A.V., Filgueiras, T.S., Nogueira, P.E. \& Fagg, C.W. 2008. Flora vascular do Bioma Cerrado: Checklist com 12.356 espécies. In: S.M. Sano, S.P. Almeida \& J.F. Ribeiro (eds.). Cerrado: ecologia e flora. Embrapa Cerrados, Brasília, pp. 423-1279.

Miranda, I.S \& Absy, M.L. 2000. Fisionomia das Savanas de Roraima, Brasil. Acta Amazonica 30: 423-440.

Miranda, V.C. 1909. Os campos de Marajó e a sua flora considerados sob o ponto de vista pastoril. Boletim do Museu Goeldi - Museu Paraense de Historia Natural e Ethnographia 5: 96-151.

MMA. 2007. Áreas Prioritárias para Conservação, Uso Sustentável e Repartição de Benefícios da Biodiversidade Brasileira: Atualização - Portaria MMA $\mathrm{n}^{\circ}$ 9, de 23 de janeiro de 2007. Série Biodiversidade 31. Ministério do Meio Ambiente; Secretaria de Biodiversidade e Florestas, Brasília. 
Moraes, P.L.R. 2012. Linnaeus's Plantæ Surinamenses revisited. Phytotaxa 41: 1-86.

Moreira, S.N., Pott, A., Pott, V.J. \& Damasceno-Junior, G.A. 2011. Structure of pond vegetation of a vereda in the Brazilian Cerrado. Rodriguésia 62: 721-729.

Mori, S.A., Boom, B.M. \& Prance, G.T. 1981. Distribution patterns and conservation of eastern Brazilian coastal forest tree species. Brittonia 33: 233-245.

Morim, M.P. 2006. Leguminosae arbustivas e arbóreas da floresta atlântica do Parque Nacional do Itatiaia, sudeste do Brasil: padrões de distribuição. Rodriguésia 57: 27-45.

Morrone, J.J. 2004. Panbiogeografia, componentes bióticos y zonas de transición. Revista Brasileira de Entomologia 48: 149-162.

Munhoz, C.B.R. \& Felfili, J.M. 2008. Fitossociologia do estrato herbáceo subarbustivo em campo limpo úmido no Distrito Federal, Brasil. Acta Botanica Brasilica 22: 905-913.

Nobre, A.V.M., Sartori, A.L.B. \& Resende, U.M. 2008. As espécies de Desmodium Desv. (LeguminosaePapilionoideae-Desmodieae) ocorrentes no Mato Grosso do Sul. Iheringia, Série Botânica 63:37-67.

Oliveira, A.A. 2000. Inventários quantitativos de árvores em matas de terra firme: histórico com enfoque na Amazônia brasileira. Acta Amazonica 30: 543-567.

Pennington, T.D. 1997. The Genus Inga. Botany. Royal Botanical Garden, Kew.

Perez, A.P.F. 2009. O gênero Zornia J.F. Gmel. (Leguminosae, Papilionoideae, Dalbergieae): Revisão taxonômica das espécies ocorrentes no Brasil e filogenia. Tese de Doutorado, Universidade Estadual de Campinas, Campinas.

Perez, A.P.F. 2012. Zornia. Lista de Espécies da Flora do Brasil. Jardim Botânico do Rio de Janeiro. Disponível em http://floradobrasil.jbrj.gov.br/2012/FB023214 (acesso em 18.09.2012).

Pires, J.M. \& Prance, G.T. 1985. The vegetation types of the Brazilian Amazon. In: G.T.Prance \& T.E. Lovejoy (eds.). Key environments Amazonia. Pergamon Press, New York, pp. 109-145.

Pires, J.M. 1973. Tipos de vegetação da Amazônia. Publicações Avulsas do Museu Paraense Emílio Goeldi 20: 179-202.

Prance, G.T. 1982. Forest refuges: Evidence from woody Angiosperms. In: G.T. Prance (ed.). Biological diversification in the tropics. Columbia University Press, New York, pp.137-156.

Queiroz, L.P. 2006. The Brazilian caatinga: phytogeographical patterns inferred from distribution data of the Leguminosae. In: R.T Pennington, G.P. Lewis \& J.A. Ratter (eds.). Neotropical savannas and dry forests: plant diversity, biogeography, and conservation. Taylor \& Francis CRC Press, Oxford, pp. 121-157.
Queiroz, L.P. 2009. Leguminosas da caatinga. Universidade Estadual de Feira de Santana, Feira de Santana.

RADAMBRASIL. 1974. Folha SA. 22. (Geologia, geomorfologia, pedologia, vegetação e uso potencial da terra). Volume 5. Ministério de Minas e Energia, Rio de Janeiro.

Ramirez, N. 1995. Revision Taxonomica del Genero Alexa Moq. (Fabaceae, Sophoreae). Annals of the Missouri Botanical Garden 4: 549-569.

Rossato, D.R., Toniato, M.T.Z. \& Durigan, G. 2008. Flora fanerogâmica não-arbórea do cerrado na Estação Ecológica de Assis, estado de São Paulo. Revista Brasileira de Botânica 31: 409-424.

Rossetti, D.F., Almeida, S., Amaral, D.D., Lima, C.M. \& Pessenda, L.C.R. 2010. Coexistence of forest and savanna in an Amazonian area from a geological perspective. Journal of Vegetation Science 21: 120-132.

Salomão, R.P., Silva, M.F.F. \& Rosa, N.A. 1988. Inventário ecológico em floresta pluvial tropical de terra firme, Serra Norte, Carajás, Pará. Boletim do Museu Paraense Emílio Goeldi - Série Botânica 4: 1-46.

Secco, R.S. \& Mesquita, A.I. 1983. Notas sobre a vegetação de canga da Serra Norte - I. Boletim do Museu Paraense Emílio Goeldi - Série Botânica 59:1-13.

Silva, M.F. \& Graham, A. 1980. Jacqueshuberia Ducke (Leguminosae - Caesalpinioideae), um gênero exclusivamente neotropical. Acta Amazonica 10: 747-754.

Sioli, H. 1964. General features of the delta of the Amazon. Scientific problems of the humid tropical zone deltas and their implications. Proceedings of the Dacca Symposium. UNESCO, Dacca, pp. 381-390.

Sylvestre, L.S. 2002. Estudos taxonômicos e florísticos das pteridófitas brasileiras: desafios e conquistas. In: E.L. Araújo, A.N. Moura, E.V.S.B. Sampaio, L.M.S. Gestinari \& J.M.T. Carneiro (eds.). Biodiversidade, conservação e uso sustentável da flora do Brasil. LIII Congresso Nacional de Botânica/ XXV Reunião Nordestina de Botânica. Recife, pp.194-195.

Tannus, J.L.S. \& Assis, M.A. 2004. Composição de espécies vasculares de campo sujo e campo úmido em área de cerrado, Itirapina - SP, Brasil. Revista Brasileira de Botânica 27: 489-506.

Thiers, B. 2012. Index Herbariorum: a global directory of public herbaria and associated staff. New York Botanical Garden's Virtual Herbarium. http://sweetgum.nybg.org/ ih/ (acesso em 15.09.2012). 
